\title{
AVALIAÇÃO DO TEBUTIURON COMO HERBICIDA E SEUS EFEITOS SOBRE OS TEORES DE MATÉRIA SECA, CARBOIDRATOS SOLÚVEIS E PROTEINA EM CAPIM COLONIÃO, $\mathscr{D}_{\text {anioum maximum, Jacq }}$
}

\author{
GUILHERME LUIZ GUIMARÃES
}

Orientador: OTTO JESU CROCOMO

Dissertação apresentada à Escola Superior de Agricultura "Luiz de Queiroz", da Universidade de São Paulo, para obtenção do título de Mestre em Nutriçāo Animal e Pastagens.

P I R A C I C A B A

Estado de São Paulo - Brasil

Junho - 1982 
À minha mãe

e a meu pai, in memorian, OFEREÇO
A minha esposa Maria Beatriz, que sempre soube me compreender, estimular e encorajar nas horas difíceis e às minhas filhas, Luciana, Renata e Cristina 
AGRADECIMENTOS

Agradeço:

- ao Professor da ESALQ Dr. Otto Jesu Crocomo pela orientação e apoio dado durante a realização deste trabalho.

- ao Professor da ESALQ Dr. Luiz Eduardo Gutierrez pelo auxí.. lio, críticas e sugestões que enriqueceram o presente relato.

- ao Centro de Energia Nuclear na Agricultura (CENA) e Escola Superior de Agricultura "Luiz de Queiroz" (ESALQ), pelas facilidades oferecidas.

- ao Professor Dr. Irineu UmbertoPacker pela valiosa colaboração dada na elucidação da análise estatística.

- ao colega e Assessor de Pesquisa Agropecuária da Elanco Quí mica Ltda., Arquimedes Lavorenti, pelo incentivo e colabora ção dada na realização da análise estatística.

- ao Professor Dr. Vidal Pedroso Farias pelas sugestões apresentadas.

- à Elanco Química Ltda. pelas facilidades oferecidas para a realização desta dissertação.

- ao amigo e Ex-Diretor de Regulamentação e Registro da Elanco Química Itda. Aldo Alves, pelo incentivo.

- aos Técnicos de Laboratório Carlos Alberto Dorelli e Clarice Matria pelos auxílios prestados em todas as fases do tra balho de laboratório.

- à Sra. Marília Magalhães Rodrigues, Secretária da Elanco Química Ltda. pela datilografia dos originais deste trabatho e pela amizade. 
- ao amigo Antonio Celso de Labio Silveira, in memorian, pela amizade, incentivo e colaboração nos trabalhos de campo.

- ao amigo Salvino Antonio Silva, Gerente de Pesquisa da Elanco Química Ltda. pela colaboração dada na determinação e avaliação das plantas daninhas

- a todos que de algum modo contribuiram para esta realização. 


\section{INDICE}

Página

LISTA DE TABELAS $\ldots \ldots \ldots \ldots \ldots \ldots \ldots \ldots \ldots \ldots \ldots \ldots$ vi

LISTA DE FIGURAS $\ldots \ldots \ldots \ldots \ldots \ldots \ldots \ldots \ldots \ldots \ldots \ldots$ vii

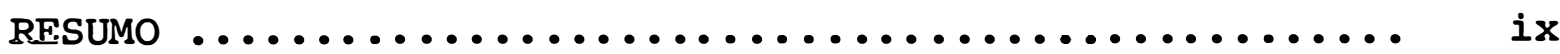

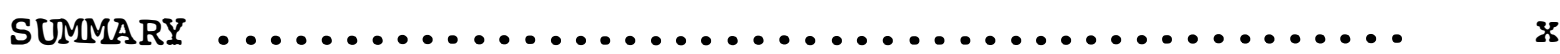

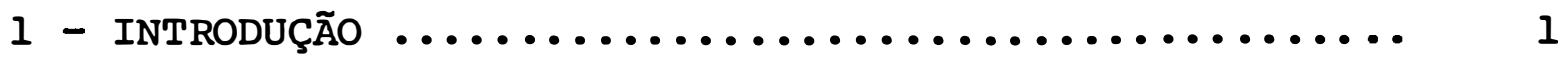

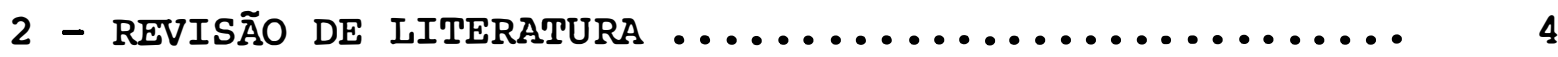

2.1 - o Capim colonião (Panicum maximum Jacq)..... 4

2.2 - Tebutiuron, o produto ................. 12

2.3 - Interação gramínea $x$ produto ............. 22

3 - MAterials E mÉtOdos ........................ 30

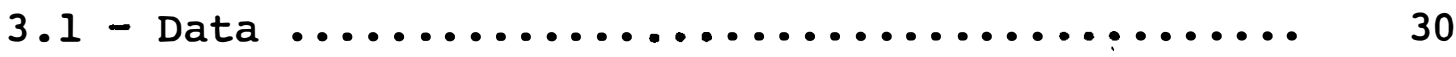

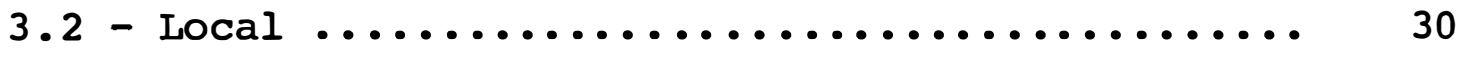

3.3 - Material Experimental ................ 30

3.4 - Concentrações ....................... 30

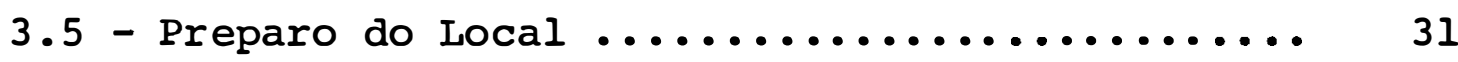

3.6 - Delineamento Estatístico ............... 31

3.7 - Distribuição dos Grânulos .............. 31

3.8 - Plantas Daninhas presentes na área do ensaio 33

3.9 - Temperatura e Chuva .................. 34

3.10 - Tempo e altura dos cortes ............... 34

3.11- Determinações e Amostragem ............... 34

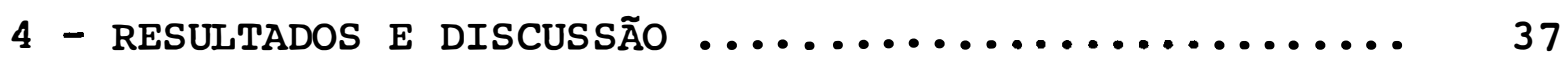

4.1 - Porcentagem de matéria seca ............. 37

4.2 - Porcentagem de carboidratos solúveis na matēria seca .......................... 40

4.3 - Porcentagem de Proteína ................. 44

4.4 - Desempenho do Tebutiuron ............... 49

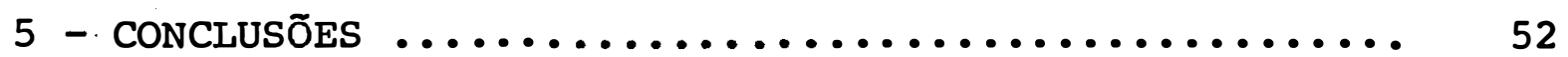

6 - Literatura CitADA .......................... 54

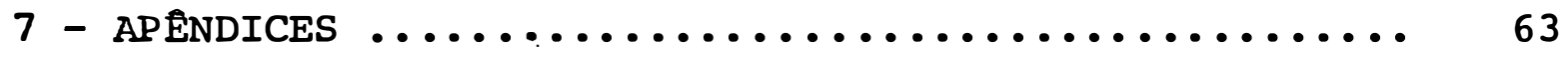




\section{LISTA DE TABELAS}

TABELA NQ

PÃGINA

1 Distribuição do capim-colonião em certas regioẽs no Brasil .................

2 Temperaturas mínimas e máximas diárias, médias mensais dos meses em que ocorreram as t.c.c. máximas e mínimas, médias dos 5 anos estudados................. 10

3 Composição bromatológica do capim-colonião em diversas idades .............

4 Solubilidade do Tebutiuron ...........

5 Lixiviação do Tebutiuron em solo argilo-

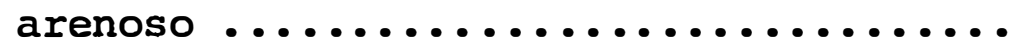

6 Produção de Panicum maximum por intervalos durante os primeiros 100 dias após o tratamento com três doses de Tebutiuron aplicado em três datas diferentes duran te a primavera de 1974 e $1975 \ldots . . . . . .$.

7 Concentração de proteína em Panicum colo. ratum em 2 intervalos durante os primeiros 100 dias após tratamento com três do ses de Tebutiuron aplicado em 2 datas di ferentes durante a primavera de 1974 ...

8 Fitotoxidade do Tebutiuron aplicado em Panicum maximum ................. 
9 Porcentagem de superfície coberta por Panicum maximum após aplicação de Te-

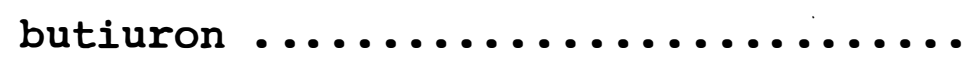

10 Efeito do Tebutiuron no controle dos

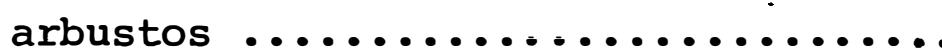

11 Resultados obtidos para porcentagem de matéria sêca com os dados represen tando a média de 4 repetiçoẽs .......

12 Análise de variância para matéria sêca

13 Resultados obtidos para porcentagem de carboidratos solúveis na matéria sê ca com os dados representando a mé dia de 4 repetiçoẽs...............

14 Análise de variância para carboidra tos solúveis .................

15 Resultados obtidos para porcentagem de proteína na matéria sêca, com os dados representando a média de 4 repe

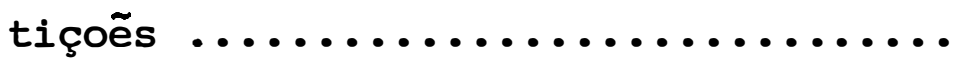

16 Análise de variância para porcentagem de proteína .................. 46

17 Fitotoxidade e Eficácia do Tebutiuron 
IISTA DE FIGURAS

\section{FIGURA}

.No

PĀGINA

1 Caminho metabólico do Tebutiuron em animais ............................ 14

2 Esquema de substituição dos radicais $R_{1}, R_{2} e$ $R_{3}$ para formação do Tebutiuron ............ 15

3 Degradação de Tebutiuron no solo ............ 21

4 Distribuição das parcelas no campo ......... 32

5 Variação do teor de matéria seca em $\underline{P}$. maximum em cortes sucessivos ................... 39

6 Variação do teor de carboidratos em relação à matéria seca em $\underline{\text {. maximum }}$............... 43

7 Mecanismo geral da ação da redutase de nitrato

8 Variação do teor de proteína na matēria seca

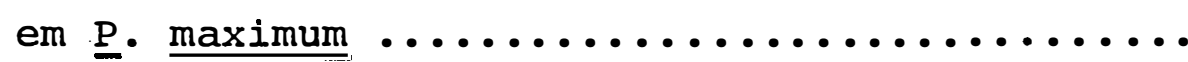




\begin{abstract}
AVALIAÇÃO DO TEBUTIURON COMO HERBICIDA
E SEUS EFEITOS SOBRE OS TEORES DE MATEE RIA SECA, CARBOIDRATOS SOLÚVEIS E PROTEINA EM CAPIM COLONIÃO, Panicum maximum, Jacq.
\end{abstract}

Guilherme Luiz Guimarães

Orientador: Dr. Otto Jesu Crocomo

RESUMO

Tebutiuron foi aplicado como "pellet" a $20 \%$ em Capim colonião, Panicum maximum Var. trichoglume, já instalado, nas doses de $0,0-1,2-2,4$ e $4,8 \mathrm{~kg} / \mathrm{ha}$ de ingrediente a tivo. A gramínea sofreu 3 cortes subsequentes a cada 45 dias. As plantas daninhas Amaranthus spinosus, Sida rhombifolia L , Emilia sonchifolia DC, Ageratum conyzoides I, Bidens pilosa, Erechtites hieracifolia, Erigeron bonariensis e Ipomoea purpu rea lam foram controladas nas doses de 2,4 e $4,8 \mathrm{~kg} / \mathrm{ha}$ de tebutiuron, com exceção de Rhinchelitrum roseum que teve um con trole considerado fraco. A dose de $4,8 \mathrm{~kg} / \mathrm{ha}$ provocou injüria moderada na gramínea, que se recuperou ao final do experimento. Os teores de matéria seca e carboidratos solúveis não foram afetados pelo produto em todas as doses testadas; o teor de proteínas teve um aumento estatisticamente significante ( $P$ $(0,05)$ na dose de $4,8 \mathrm{~kg} / \mathrm{ha}$, principalmente nos primeiros 90 dias de teste, equivalendo-se às demais doses aos 135 dias. As doses de $0,0-1,2$ e $2,4 \mathrm{~kg} / \mathrm{ha}$ de Tebutiuron não afetaram o teor de proteínas. A melhor dose testada foi de $2,4 \mathrm{~kg} / \mathrm{ha}$ do Tebutiuron. 
EVALUATION OF TEBUTHIURON AS A HERBICIDE AND HIS EFFECTS ON THE DRY MATTER; SOLUBLE CARBOHIDRATES AND PROTEIN LEVELS ON pianicum maximum Jacq.

Guilherme Luiz Guimarães

Adviser: Dr. Otto Jesu Crocomo

SUMMARY

Tebuthiuron was applied, as $20 \%$ pellets, on installed green panic, Panicum maximum var. trichoglume, at rates $0,0-1,2-2,4$ and $4,8 \mathrm{~kg}$ ia/ha; the grass was cut 3 times with a 45 days interval. The weeds Amaranthus spinosus, Sida sonchifolia, DC, Ageratum conyzoides L, Bidens pilosa, , Erechtites hieracifolia, Erigeron bonariensis and Ipomoea pur. purea Lam were controlled at rates of 2,4 and and $4,8 \mathrm{~kg} / \mathrm{ha}$, except Rhynchelitrum roseum which control was poor. In the rate of $4,8 \mathrm{~kg} / \mathrm{ha}$ Tebuthiuron produced a moderate injury in the green panic but the grass had a good recuperation at the end of the trial. The percent of dry matter and soluble carbo hidrates were not affected by the product in all tested rates. The level of protein was significant $(P<0,05)$ increased mainly during the first 90 days; this level was equivalent for all doses after 135 days. The rates of $0,0-1,2$ and 2,4 $\mathrm{kg} / \mathrm{ha}$ of Tebuthiuron did not affect the percent of protein . The best tested dose was $2,4 \mathrm{~kg} / \mathrm{ha}$ of Tebuthiuron. 
บ. INTRODUÇ̃̃̃

Estima-se que $20 \%$ das terras brasileiras, cerca de 165 milhões de hectares estejam hoje ocupados com pastagens sendo que 117 milhões de hectares (71\%) são de pastagens naturais e 48 milhões de hectares (29\%) de pastagens artificiais.

Todavia apesar da imensa área ocupada pelas pastagens, a produtividade desses pastos deixa muito a desejar; falta de um manejo adequado, falta de recursos econômicos canalizados para o setor, total desconhecimento de novas técni cas, problemas sociais são alguns fatores que concorrem para uma baixa produtividade.

Numa época em que há necessidade de se produzir alimentos não somente para atender o mercado interno mas também para exportar um excedente que se deseja ser grande, necessitamos também buscar alternativas para a substituição de petróleo e seus derivados.

Em termos globais, a demanda de alimentos cresce proporcionalmente ao aumento da população e com base nas tendências atuais a população mundial duplicará dentro de 38 anos; pergunta-se então como poderemos duplicar a oferta de alimentos num período tão curto ?

Essencialmente, hā duas maneiras para se aumentar a produção de alimentos: aumento da produtividade e ocupação de novas áreas. 
A produtividade, nos principais países produto res de alimentos (Estados Unidos, Canadá, França, Argentina , Austrália), já atingiu níveis bastante altos. Por outro lado - Brasil possui, dos 240 milhões de hectares de cerrados ou coberturas vegetais similares, 50 milhões de hectares de ter ras aptas ao cultivo agrícola. Cabe ao Brasil um papel importante no rumo atual da produção de alimentos no mundo e nesse contexto a melhoria de nossas pastagens ganha um destaque mui to especial levando-se em conta as 117 milhões de cabeças de gado que nelas existem.

Um dos grandes problemas entretanto, enfrentado pelos pecuaristas è a proliferação de plantas rasteiras e arbustivas daninhas nos pastos, que tem tomado grande área de nossas pastagens, impedindo um pastoreio livre; muitas des sas plantas são altamente tóxicas e provocam invariavelmente a morte de muitos animais.

Há por outro lado, em certas regiões, uma excassez de mão-de-obra o que impede o agricultor de eliminar boa parte dessas plantas daninhas; mesmo em regiões onde a mão-de-obra ainda representa um efetivo bastante grande, o custo desse tipo de controle é muito alto e muitas vezes antí econômico, além de se repetir anualmente devido a rebrota das plantas daninhas.

Uma das alternativas de que dispõe o agricultor è utilizar-se de produtos químicos, herbicidas e/ou arbus ticidas que são muitas vezes seletivo e eliminam grande parte das plantas daninhas.

Mas até onde o uso de produtos químicos afeta o pasto, sua digestibilidade, seu teor de proteína, carboidra tos, fibras, é uma questão ainda não abordada. A pesquisa que tem sido feita para se verificar o efeito de produtos químicos na composição química das plantas, bem como no seu metabo lismo, é reduzida; alguma pesquisa que exista neste setor é praticamente toda importada, existindo pouco ou quase nada 
realizado em termos de Brasil.

Com a finalidade de verificar o comportamento de uma gramínea frente a un arbusticida foi que nos propusemos a realizar o presente trabalho.

A graminea escolhida foi o capim-colonião, $\mathrm{Pa}-$ nicum maximum Jacques por ser ela una das mais representativas de nossas pastagens, tanto natural como artificial; o arbusticida utilizado foi un composto derivado de uréia, o Tebu tiuron, que se tem mostrado muito promissor no combate princi palmente a plantas arbustivas em pastagens. Este produto já é largamente utilizado na cultura de cana-de-açucar, sendo que foi totalmente desenvolvido em nossas condições.

Além de avaliar o desempenho do Tebutiuron como herbicida/arbusticida, a sua ação sobre os teores de proteína, carboidratos solúveis e matéria-seca foi também o obje tivo do presente trabalho. 
2. REVISÃO DE LITERATURA

2.1. CAPIM COLONIÃO (Panicum maximum Jacq)

o capim-colonião, Panicum maximum Jacq, parece ser originārio do Congo e de outros países africanos, dos quais foram posteriormente disseminados para outras partes do globo.

A introdução do capim-colonião no Brasil deve ter ocorrido provavelmente na região da Bahia, durante o governo de Tomé de Souza; isto é o que mostra FURLAN (1969) citando VILLARES; o colonião teria servido como cama para escra vos vindos da região de Angola e Guiné.

o capim-colonião tem grande capacidade de adaptação e é hoje encontrado em quase todo o território nacional como pode ser visto na Tabela 1.

OTERO (1961) coloca como grandes características dessa gramínea a extraordinária resistência ao fogo e ao pisoteio, a grande rusticidade e produção de forragem e facilidade de multiplicação, indicando como utilidade principal a formação de pastagens, prestando-se também ao fornecimento de forragem verde quando cortado ainda novo e tenro. 
Tabela 1. Distribuição do capim-colonião em certas regiões,no Brasil

Região

\& de Área com P. m maximum

Sudeste do Mato Grosso do Sul

Oeste de São Paulo

61

Sudoeste de Goiás

Triângulo Mineiro

São Miguel do Araguaia/Crixás

Norte de Minas Gerais

Nordeste de Minas Gerais

Teófilo Otoni/Nanuque/Carlos Chagas

Pedra Azul/Almenara

FONTE: Elanco Química Ltda. Divisão de Marketing - 1978

E uma gramínea forrageira perene, tropical , incluída entre aquelas de maior potencial produtivo; é um capim que se adapta bem em regiões quentes, livre de geadas,com solos que apresentam fertilidade de média a alta, com boa drenagem e textura arenosa. Segundo a revista AGROCERES muitas áreas de colonião estão sendo invadidas por outros capins e várias plantas nativas; isto deve ter ocorrido provavelmente devido ao mau manejo dos pastos e queda na fertilida de do solo.

De acordo com o sistema de ENGLER, MITIDIERI (1977), classifica o colonião do seguinte modo:

$\begin{array}{ll}\text { DIVISÃO: } & \text { Angiospermae } \\ \text { CLASSE: } & \text { Monocotylodeoneae } \\ \text { ORDEM: } & \text { Graminales (Poales, Glumiforae) } \\ \text { FAMILIA: } & \text { Gramineae (Poaceae) } \\ \text { SUB-FAMILIA: } & \text { Panicoideae }\end{array}$




$\begin{array}{ll}\text { TRIBO: } & \text { Paniceae } \\ \text { GENERO: } & \text { Panicum } \\ \text { ESPÉCIE: } & \text { Panicum maximum, }\end{array}$

Dentre as variedades de $\underline{\mathrm{P}}$ - maximum existentes e que segundo TIBAU (1978) são em número superior a 40 , encon tra-se o Panicum maximum wariedade trichoglume, também conhecido como "green panic"; esta graminea tem 1,50 a 2,00m de al. tura, suas folhas são finas e suaves e os talos mais delgados. De acordo com a excelente revisão de LEMOS e CORSI (1981) o capim-colonião è uma planta perene com sistema radicular profundo, formando grandes touceiras, com - colmos que saem de rizomas curtos; os colmos são semi-geniculados , eretos duros, e com folhas em toda sua extensão, glabros ou glancos, de secção elíptica e grandes nós esbranquiçados; as bainhas compridas, glabras e levemente estriadas, IÍgula alia da e brancacenta, medindo $4 \mathrm{~mm}$.

Essa gramínea, assim como a maioria das gramíneas forrageiras tropicais florescem e frutificam apōs se desenvolverem durante todo o verão.

Segundo TIBAU (1978), o colonião tem como características básicas o seu extraordinário poder de propaga ção e dominante agressividade, cobrindo todos os vazios que são postos a seu alcance, inclusive aqueles ocupados por outros capins e se infiltra com facilidade nas capoeiras, desde que the satisfaçam as exigências mínimas de fertilidade e con dições físicas do solo.

MITIDIERI (1977) descrevendo algumas das principais cêracterísticas agronômicas do capim-colonião, cita que esta gramínea è propícia de clima tropical quente e úmido, com temperatura média anual de $18^{\circ} \mathrm{C}$ e com precipitação pluvio

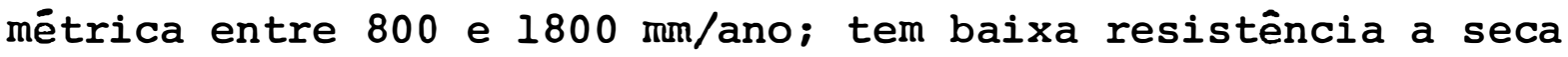
e a geada e baixa tolerância ao encharcamento.

Segundo McCOSKER e TEITZEL (1975), o capim-colonião adapta-se a um grande número de tipos de solo mas a 
produção em solos de baixa fertilidade é bastante prejudicada e apresenta acentuada resposta à fertilização.

Alguns aspectos anatômicos do capim-colonião no que se refere às suas características fotossintéticas, deverão ser considerados. Sendo uma planta $C_{4}$, como demonstram LUDLOW e WILSON (1972), DOWNTON (1975), WILSON (1975), LUDLOW e NG (1976), entre outros, apresenta como importante característica uma anatomia foliar, denominada Anatomia KRANZ, onde há uma possível divisão de trabalho entre os cloroplastos dos dois tipos de célula existentes, conforme relata

LAETSCH (1974), citando HABERLANDT (1904). Ainda segundo LAETSCH (1974) essa particular anatomia vista nas plantas $\mathrm{C}_{4}$ consta de um arranjamento radial do clorenquima ao redor do feixe vascular; o clorenquima, por seu turno está diferenciado em uma camada interna de células grandes, cilíndricas, de paredes grossas contendo cloroplastos proeminentes e uma ou mais camadas externas de células semelhantes as paliçadicas. Salienta ainda o mesmo autor o direto e rápido transporte de fe tossintatos assimilados nos tecidos para os vasos; isto pressupõe um aumento da taxa fotossintética como resultado da rápida remoção dos produtos finais; há ainda evidências de que a Anatomia Kranz tenha relações com certas condições ambientais.

Outras catacterísticas apresentadas pelas plan tas $C_{4}$, conforme revisão de GUIMARÃES (1977) são saturação e altas intensidades luminosas, performance ótima em temperaturas oscilando entre 30 e $40^{\circ} \mathrm{C}$, menor requerimento de unidades de água para a produção de uma unidade de matéria-seca,a assí milação de $\mathrm{CO}_{2}$ atinge $60-100 \mathrm{mg} \mathrm{CO}_{2} / \mathrm{dm}^{2} / \mathrm{h}$, quando medido nas condições ótimas (taxas fotossintéticas), fotorespiração praticamente ausente, apresentando baixo ponto de compensação de $\mathrm{CO}_{2} \cdot$

Todas essas características que são peculiares às plantas $C_{4}$ parecem conferir-lhes uma maior produtividade. principalmente se confrontadas com as chamadas plantas $\mathrm{C}_{3}$, co 
mo mostra LUDLOW e NG (1976) que trabalharam com essas duas espécies de plantas e concluiram que a produção de matéria-se ca na gramínea $c_{4}$ foi duas vezes maior do que em leguminosas $\mathrm{c}_{3} \cdot$

EL-SHARKAWY et alii (1967) mostraram que foIhas iluminadas de milho e outras que não liberam $\mathrm{CO}_{2}$ en $\mathrm{CO}_{2}$ livre de ar, começam a liberar $\mathrm{C}_{2}$ quando tratadas com 0 inibidor fotossintético 3-(3,4 diclorofenil)-l-dimetil uréia (DCMU). Esses pesquisadores concluiram que $0 \mathrm{CO}_{2}$ liberado na presença de DCMU representa $\mathrm{O}^{\mathrm{CO}_{2}}$ respiratório liberado pelo processo normal de respiração no escuro. RYLE e HESKETH (1969) demonstraram que a deficiência de nitrogênio causou uma redução na taxa de assimilação de dióxido de carbono em milho, uma planta $\mathrm{C}_{4}$.

.Entretanto, vārios fatores e substāncias podem alterar ou afetar a taxa fotossintética das plantas $\mathrm{C}_{4}{ }^{\prime}$ como o capim-colonião. WILSON (1975) mostra a influência da temperatura e do nitrogénio sobre o crescimento, a fotossíntese e a acumulação de carboidratos não estruturais sobre panicum ma ximum var. trichoglume.

Pode-se verificar portanto que produtos deriva dos da uréia podem interferir no processo fotossintético de gramíneas como veremos com mais detalhes adiante.

Segundo LEMOS e CORSI (1981) uma das características que se destaca no capim-colonião, assim como na maio ria das forrageiras atualmente cultivadas è sua acentuada estacionalidade de produção de matéria-seca durante o ano, que se caracteriza por altas produções no período quente e úmido (verão) e baixas produções no período de baixas temperaturas e baixa precipitação pluviométrica (inverno); a escassez de produção no inverno ocorre quando um ou mais fatores de crescimento passa a ser limitante da produção, principalmente a luminosidade, temperatura e ăgua.

PEDREIRA (1972) verificou que quando a taxa de 
crescimento da cultura é máxima, a temperatura mínima diária está em torno de $18,2^{\circ} \mathrm{C}$ e a máxima em torno de $29,2^{\circ} \mathrm{C}$; quando a taxa de crescimento é mínima, a temperatura mínima diária está em torno de $10,5^{\circ} \mathrm{C}$ e a máxima em torno de $24,9^{\circ} \mathrm{C}$, como pode-se notar na Tabela 2.

PETERSON (1970) relata que para pastos de clí ma temperado a temperatura ideal de crescimento oscila entre 20 e $35^{\circ} \mathrm{C}$.

As produções devem também estar dentro dos padrões desejāveis de qualidade e quantidade, principalmente no que se refere a variação da composição bromatológica e digestibilidade das plantas forrageiras.

BOSE (1971), em extensa revisão bibliográfica, verificou que no Brasil, as gramineas tropicais têm geralmente seus melhores valores em proteína, carboidrato e digesti bilidade quando ainda novas e valores inferiores após a brotâ ção; o autor achou os seguintes dados para o capim-colonião (Ver Tabela 3).

JARDIM et alii (1965) consideraram deficientes em proteína bruta para bovinos, as pastagens com menos do que $8 \%$ desse nutriente na matéria-seca. Para os animais em cresci mento, precoces e exigentes, são necessários níveis mais elevados.

JOHNSON et alii, citados por. LEMOS e CORSI (1981), trabalhando nas Filipinas, verificaram o valor do capim colonião para alimentação do gado, nos trópicos durante a estação úmida. o conteúdo da matéria-seca na forragem verde permaneceu quase constante $(20$ a $22 \%)$ durante os primeiros 60 dias de seu crescimento, enquanto o conteúdo de proteína crua decresceu de cerca de $10 \%$ aos 20 dias para cerca de 6,5\% aos 60 dias.

SERRÃO e PALESI (1977) destacaram a importância e o potencial produtivo da região do trópico úmido "brasileiro que compreende praticamente toda a região amazônica, onde o ca 
Tabela 2. Temperaturas mínimas e máximas diārias, médias men sais dos meses em que ocorreram as t.c.c. máximas e minimas, médias dos cinco anos estudados

\begin{tabular}{|c|c|c|c|}
\hline & & $\begin{array}{l}\text { Quando a t.c.c. } \\
\text { é máxima }\end{array}$ & $\begin{array}{l}\text { Quando a t.c.c. } \\
\text { é minima }\end{array}$ \\
\hline \multirow[t]{2}{*}{ COL. } & temp. min. & 19,3 & 10,8 \\
\hline & temp. máx. & 29,4 & 24,9 \\
\hline \multirow[t]{2}{*}{ GOR. } & temp. min. & 17,6 & 9,8 \\
\hline & temp. māx. & 29,8 & 24,5 \\
\hline \multirow[t]{2}{*}{ JAR. } & temp. min. & 18,7 & 11,6 \\
\hline & temp. māx. & 28,6 & 25,8 \\
\hline \multirow[t]{2}{*}{ PAN. T. } & temp. min. & 17,2 & 9,8 \\
\hline & temp. māx. & 29,1 & 24,5 \\
\hline \multirow[t]{2}{*}{ MÉDIA } & temp. min. & 18,2 & 10,5 \\
\hline & temp. máx. & 29,2 & 24,9 \\
\hline
\end{tabular}

FONTE: PEDREIRA, J.V.S. (1972)

pim-colonião ocupa $85 \%$ das pastagens cultivadas. Entretanto, esse potencial não tem sido aproveitado de modo adequado e tem-se observado uma degradação geral das pastagens da região, positivamente correlacionada com a infestação de plantas invasoras.

As tentativas para recuperação das pastagens de gradadas têm girado em torno do controle das plantas invasoras por meios manuais físicos e químicos, seguido de um período de descanso com a finalidade de reduzir a competição e favo recer um melhor desenvolvimento do colonião. 
Tabela 3. Composição bromatológica de Capim-Colonião em diversas idades

\begin{tabular}{|c|c|c|c|c|c|}
\hline \multirow{2}{*}{$\begin{array}{l}\text { Dias de Cres- } \\
\text { cimento }\end{array}$} & \multirow{2}{*}{$\begin{array}{l}\text { o de mat. } \\
\text { seca }\end{array}$} & \multicolumn{4}{|c|}{ Composicão em \& na matéria-seca } \\
\hline & & Proteína & $\begin{array}{l}\text { Extrato } \\
\text { Etéreo }\end{array}$ & Fibra & $E \mathbf{N}$ \\
\hline 26 & 17,8 & 30,7 & 4,1 & 19,4 & 26,3 \\
\hline 31 & 16,4 & 30,5 & 3,5 & 19,4 & 29,5 \\
\hline 39 & - & 22,1 & 4,1 & 27,4 & 31,4 \\
\hline 50 & 16,4 & 17,7 & 2,8 & 33,5 & 34,2 \\
\hline 55 & 16,9 & 16,6 & 3,4 & 35,8 & 33,4 \\
\hline 60 & 17,3 & 14,9 & 3,0 & 36,1 & 34,5 \\
\hline 68 & 17,0 & 12,6 & 2,9 & 44,5 & 30,9 \\
\hline 75 & 16,8 & 14,6 & 1,7 & 41,1 & 32,1 \\
\hline 80 & 19,2 & 12,9 & 2,8 & 40,7 & 36,3 \\
\hline 89 & 21,4 & 12,6 & 2,7 & 40,3 & 36,8 \\
\hline 97 & 21,5 & 11,2 & 2,9 & 42,8 & 36,0 \\
\hline 103 & 21,5 & 10,1 & 2,9 & 42,3 & 37,2 \\
\hline 110 & 22,0 & 11,1 & 2,9 & 42,7 & 35,8 \\
\hline 117 & 27,2 & 10,4 & 1,9 & 43,3 & 36,7 \\
\hline 123 & 26,1 & 10,5 & 1,7 & 39,0 & 39,9 \\
\hline 132 & 26,6 & 8,9 & 2,8 & 42,9 & 37,9 \\
\hline 138 & 28,1 & 8,8 & 3,1 & 42,7 & 38,4 \\
\hline 150 & 26,6 & 8,0 & 2,5 & 43,4 & 38 \\
\hline 152 & 26,3 & 7,7 & 2,7 & 43,2 & 39,1 \\
\hline 159 & 31,3 & 6,9 & 2,7 & 43,1 & 40,2 \\
\hline
\end{tabular}

FONTE: BOSE, M.L.V. (1971) 


\subsection{TEBUTIURON O PRODUTO}

Tebutiuron è nome comum, aprovado pela ANSI, BSI, para o produto químico $\mathrm{N}-[5-(1,1$ dimetiletil), $1 \leqslant 3,4 ;-\cdots$ tiadiazol - 2 - il] $-\mathrm{N}, \mathrm{N}^{\prime}$ - dimetiluréia, com peso molecular igual a 228,3 e fórmula molecular $\mathrm{C}_{9} \mathrm{H}_{16} \mathrm{~N}_{4} \mathrm{O}$, apresentando a se guinte fórmula estrutural:<smiles>CN(C(N)=O)c1nnc(C(C)(C)C)s1</smiles>

E um sólido incolor e inodoro com ponto de fusão entre 161,5 e $164^{\circ} \mathrm{C}$ e pressão máxima de vapor de $2 \times 10^{-6} \mathrm{~mm}$ de $\mathrm{Hg}$ a $25^{\circ} \mathrm{C}$. Sua solubilidade pode ser verificada na Tabela 4

Tabela 4. Solubilidade de Tebutiuron

Solvente

clorofórmio

$(\mathrm{g} / 100 \mathrm{ml})$

Metanol

25,0

Acetona

17,0

Acetonitrilo

7,0

Metil Celosolve

6,0

Hexano

6,0

Benzeno

0,61

Água

0,37

0,23

FONTE: ELANCO QUIMICA LTDA. - 1980

Estudos toxicológicos levados a efeito por MORTON e HOFFMAN (1976) demonstraram ser o Tebutiuron um produto de baixa toxicidade para animais de laboratório e peixes; ra- 
tos, cães, coelhos e patos absorveram prontamente doses orais únicas de $10 \mathrm{mg} / \mathrm{kg}$ de tebutiuron sendo o composto rapidamente metabolizado com os metabólitos sendo eliminados pela urina e fezes de cada uma das espécies examinadas.

Após a aplicação das doses de $10 \mathrm{mg} / \mathrm{kg}$, menos que $3 \circ$ da dose radioativa dada foi excretada pelas fezes dentro de 96 horas. Em ratos, entretanto, aproximadamente 30\% da dose foi excretada pelas fezes. O composto foi extensivamente metabolizado e os metabólitos foram rapidamente excretados na urina de cada uma das espécies examinadas. Esses dados vão de encontro às observações feitas por TODD et alii. (1974), que verificaram não haver qualquer comprometimento ou acumulação de Tebutiuron ou seus metabólitos em animais, o que demonstra a baixa toxicidade do produto.

Ainda de acordo com MORTON e HOFFMAN (1976) O metabolismo de Tebutiuron foi qualitativamente similar em cada espécie examinada mas ocorreram variações nas '. propoŕções dos metabólitos encontrados na urina. Os vários caminhos pelos quais o Tebutiuron é metabolizado encontra-se na Figura 1. A $N$ demetilação na posição $N^{\prime}$ da cadeia lateral da uréia foi a principal via de metabolismo em camundongos e ratos ao passo que a $\mathrm{N}$ - demetilação na posição $\mathrm{N}$ da uréia foi o: caminho principal em patos. A única via metabólica observada em peixes foi a N-demetilação na posição $N^{\prime}$ da cadeia lateral da uréia.

Segundo BRODIE et alii, (1958) acredita-se que a reação de $\mathrm{N}$-demetilação procede através de um intermediārio $\mathrm{N}$ hidroximetil e esse composto é visto durante o metabolismo da difenamida como mostrou MC MAHON e SULLIVAN (1965) e de compostos como 1 - Naftil- $\mathrm{N}$ - meticarbamato e $\mathrm{N}$ - metilcarbazol, como estudados por DOROUGH e CASIDA (1964) e GORROD et alii, (1970) respectivamente.

RAINEY et alii (1976) administraram Tebutiuron ${ }^{14} \mathrm{C}$ a vacas leiteiras, na dose de $329,9 \mathrm{mg} / \mathrm{dia}$ a cada 12 ho- 


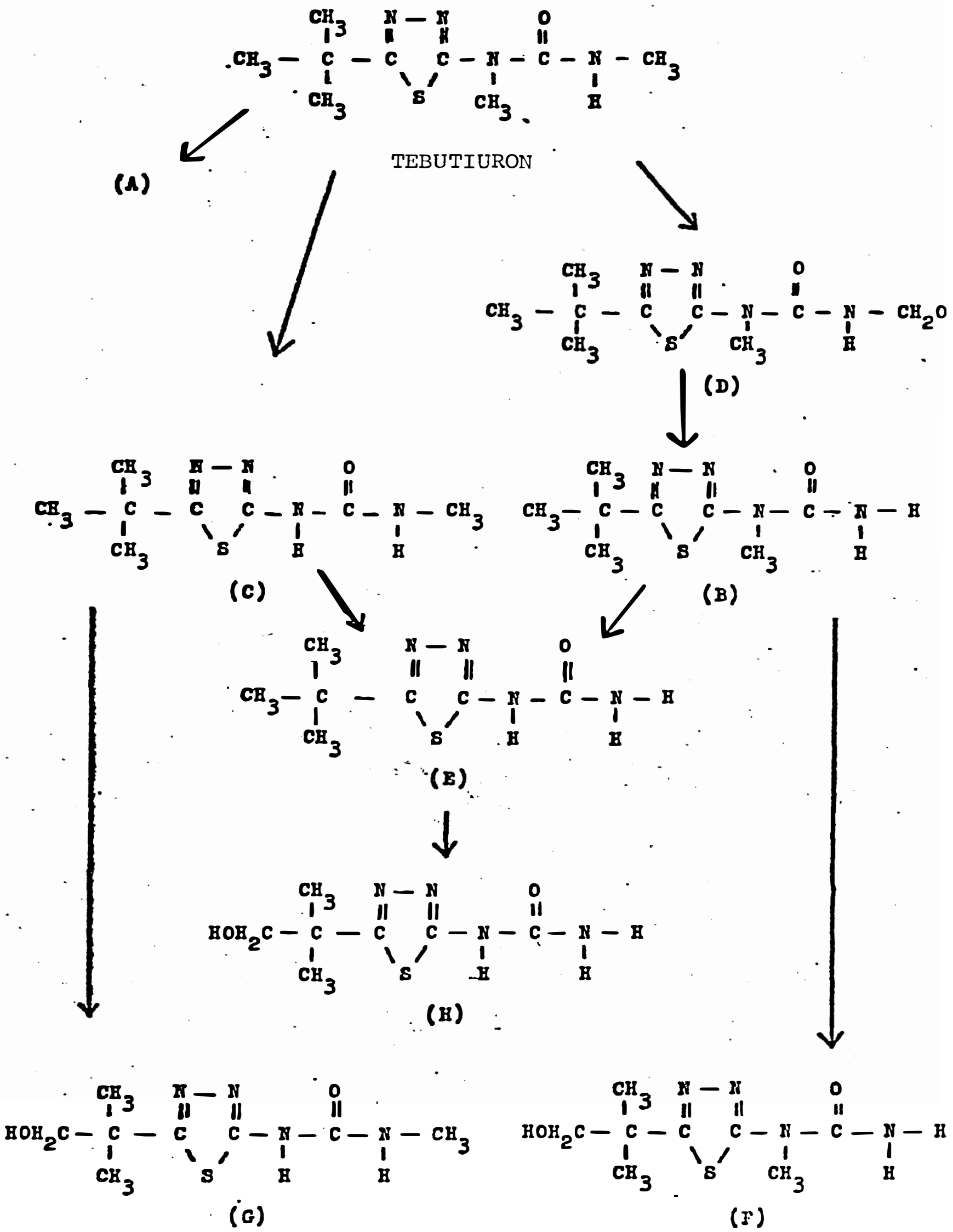


ras, por um período de 5 dias. Doze horas após administração da primeira dose o nível de radioatividade no leite foi equivalente a $0,103 \mathrm{ppm}$. Após a última administração, o resíduo caiu rapidamente e nada mais foi detectado 60 horas mais tarde. Os níveis muito baixos de Tebutiuron no leite indicaram que o composto é pronta e completamente metabolizado. o perfil metabólito encontrado no leite é consistente com aquele encontrado em estudos de metabolismo com outras espécies animais.

KLINGMAN e ASHTON (1975) teceram considerações sobre a uréia como fertilizante nitrogenado e através da substituição de 3 átomos de Hidrogênio da uréia por outros grupamentos químicos produziram-se herbicidas efetivos; os grupamentos mais comuns incluem um grupo fenil, um grupo metil e um grupo metoxi. Especificamente no caso do Tebutiuron esses 3 átomos de hidrogênio são substituídọs pelos radicais $\mathrm{CH}_{3}^{-}, \mathrm{CH}_{3}{ }^{-}$<smiles>Sc1nncs1</smiles>

conforme o esquema constantè ná :figura 2

FIGURA 2: Esquema de substituição dos radicais $R_{1}, R_{2}$ e $R_{3}$ para formação do Tebutiuron<smiles>[R1]NC(=O)N([R1])[R1]</smiles><smiles>CCCCCc1nnc(N(C)C(=O)N(C)C)s1</smiles> 
KLINGMAN e ASHTON (1975) relatam que os herbicí das derivados da uréia são relativamente não seletivos quando utilizados em doses altas e são usualmente aplicados ao solo; entretanto em doses baixas podem ser seletivos. Esta seletivi dade é obtida tanto através da proteção providenciada pela pequena ou quase nenhuma lixiviação do herbicida (que depende da característica de cada um) como também pela tolerância pro videnciada pela planta (maior ou menor, conforme a espécie).

GEISSBUHLER, et alii. (1975) mostraram ao estudar a química, a degradação e o modo de ação dos herbicidas, que o exame da atividade herbicida de compostos derivados da uréia aplicados ao solo, sob uma variedade de condições de campo demonstrou que certas propriedades e fatores ambientais do solo têm um efeito predominante não somente sobre o desempenho desses produtos, mas também sobre sua persistência, estudos sugerem que a adsorção de herbicidas derivados de uréia por certos constituintes do solo como partículas orgânicas e vários tipos de colóides de argila é um fator importante no controle de sua remoção das camadas do solo por lixiviação e na regulação de suas taxas de degradação pelos microorganismos.

GEISSBUHLER et alii (1975) prosseguem dizendo que o quilíbrio entre a adsorção e a desorpção determina a concentração de cada composto particular na solução do solo e portanto sua viabilidade à decomposição microbiana; desde que a viabilidade na solução do solo é relacionada inversamente com a adsorção espera-se que para um particular solo, sob as mesmas condições ambientais, os herbicidas-uréias mais fortemente adsorvidos são decompostos menos rapidamente pelos microorganismos.

Inúmeros são os trabalhos que puderam verificar quais microrganismos que são responsáveis pela degradação de herbicidas derivados de uréia. HILL et alii (1955) foram os primeiros a demonstrar que bactérias do gênero Pseudomonas. 
atuam sobre esses produtos. Pesquisas feitas por HILL e Mc GAHEN (1955), BOWEN, J. (1967), MURRAY et alii, (1969), TWEEDY et alii, (1970), WEINBERGER, (1972), mostraram que dentre outras, as bactérias dos gêneros Xanthomonas, Sarcina, Bacillus, Pseudomonas, Aspergillus, os fungos Talaromyces wortmanii, Fusarium oxysporum e Rhizoctonia solani são capazes de desdobrar compostos derivados da uréia.

Em relação ao Tebutiuron KLINE et alii

realizaram 3 experimentos para verificar a ação de Tebutiuron sobre microorganismos do solo. Esses testes incluiram me dida de $\mathrm{CO}_{2}$ produzido pelas culturas no solo, $\because$ determinàção das bactérias, fungos e actinomicetos nos solos e estudo do efeito do herbicida sobre culturas puras dos microorganismos. Os microorganismos selecionados para experimentos no respirô metro de Warburg foram Pseudomonas aeraginosa, Arthrobacter. globiformis, Bacillus subtilis, Azotobacter chroococcum e Streptomyces albus. Esses pesquisadores concluiram que a pro dução de $\mathrm{CO}_{2}$ dos vários solos não foi alterada pelos tratamentos com Tebutiuron, nas doses de 4 e 40 ppm. O número de microorganismos não foi afetado, nos mesmos níveis; pequena inibição na produção de $\mathrm{CO}_{2}$ foi notada em várias espécies de microorganismos do solo nos experimentos com o respirômetro de Warburg, mas isto ocorreu apenas quando foi aplicado ao solo Tebutiuron na quantidade de $40 \mathrm{ppm}$.

A pesquisa do modo de ação desses produtos vem sendo verificada há muito tempo; FREED (1952) propôs que esses compostos afetavam o metabolismo do nitrogênio. HAUN e PETERSON (1954) mostraram que monurom é rapidamente' absorvido pelas raízes de plantas de tomate e translocava-se até a parte superior da planta em 48 horas; não havia translocação em aplicações feitas nas plantas.

CRAFTS (1959) mostrou resultados, semelhantes em aveia; compostos marcados moveram-se do sítio aplicado pa ra a extremidade da folha, presumivelmente pelo apoplasto. 
Aparentemente as uréias substituídas não são capazes de entrar e se mover pelo floema.

CRAFTS e DREVER (1960) trabalhando com monuron marcado verificaram que as uréias substituídas são aparentemente capazes de se mover através das células vivas da endoderme da raiz sem dificuldades, embora elas não sejam ca pazes de entrar nas células vivas do floema, nas folhas.

Baseando-se no mecanismo de ação dentro das cé lulas das folhas, COOKE (1956) verificou que a reação de HILL foi completamente inibida em isolados de cloroplastos preparados de folhas de espinafre e utilizando-se Janus Green B como oxidante, quando tratado com monuron em baixas concentrações.

WESSELS e VAN DER VEEN (1956) verificaram que monuron e diuron inibiam a parte do processo fotossintético dependente da luz, muito mais drasticamente do que feniluretano, que foi utilizado como padrão.

ASHTON e CRAFTS (1973), GEISSBULHLER et alii. (1975), indicam ser a inibição da reação de HILI, na fotossíntese, o sítio primário de ação das uréias substituídas. Apesar do mecanismo de ação ainda não ter sido totalmente esclarecido, sabe-se que a ação das uréias substituídas envolve o sítio de evolução do oxigênio no fotosistema II. (Apêndice A). Concluiu-se em trabalhos com diuron, que este for ma complexos com a forma oxidada de um componente desconheci do localizado no caminho de transferência de eletron associa do ao fotosistema II e este componente também toma parte. no transporte de eletron cíclico; isto explicaria a inibição do transporte de eletron não-cíclico bem como o transporte de eletron cíclico que ocorre com altas concentrações de fenilu u réia.

Desde que se assuma ser a inibição da fotossín tese pela uréia devido a formação de pontes de $\mathrm{H}$ do , grupo NH e/ou oxigênio carbonil com os centros ativos nos cloro- 
plastos foi proposta a formação de pontes entre diuron e a plastoquinona no estado oxidado que por isso passa a ser um possível candidato a substāncia acima mencionada e ainda des con'secida.

Devido a essa inibição na reação de HILL, os sintomas fitotóxicos desses herbicidas são primariamente observados nas folhas, como indicam ASHTON e CRAFTS (1973); os sintomas foliares são de dois tipos: o agudo e o crônico. Os sintomas agudos estão associados com concentrações relativamente altas do herbicida na folha e aparecem dentro de poucos dias após a aplicação. Inicialmente áreas livremente ver des, tornam-se amareladas e posteriormente necróticas. Os sintomas crônicos ocorrem com concentrações foliares relativamente baixas e requerem vários dias para se desenvolver.

Um segundo tipo de clorose pode também ocorrer: há uma clorose parcial na qual a folha torna-se brilhan te ou verde-amarelada; isto deve presumivelmente ocorrer em concentrações foliares do herbicida, muito baixas. ASHTON e CRAFTS (1973), GEISSBUHLER, et alii (1975) mostram que as uréias substituídas estão sujeitas à degradação pelas plantas superiores sendo que o herbicida po de ser degradado em diferentes taxas, por várias espécies.I to é a base de certos usos seletivos de alguns desses herbicidas. Demetilação é o mecanismo primário de detoxificação para esses herbicidas. Um sistema de enzima microssômicos tem sido isolado, o qual é capaz de realizar a demetilação dos derivados de uréia; o oxigênio molecular e NADPH ou NADH são os cofatores requeridos para esta reação. Demetoxilação também ocorre nos compostos contendo um grupo metóxi. Seguin do-se a dealquilação e/ou dealquoxiação a molécula pode estar sujeita a hidrólise, a qual envolveria uma deaminização e descarboxilação produzindo a anilina correspondente; esta anilina pode ser oxidada para produzir o nitrito correspondente ou a conjugação com constituintes celulares normais. 
ANÔNIMO (1975) estudando o comportamento de: Tebutiuron no solo mostrou um esquema de degradação desse produto no solo. No esquema apresentado na figura 3 verificou-se que o principal metabólito, o metabólito A é formado pela demetilação do nitrogênio terminal. O metabólito $B$, pro duzido em menor proporção é formado do metabólito A pela hidrólise da uréia. o metabólito $C$ pode ser outro produto de degradação formado diretamente do Tebutiuron pela. demetilação do nitrogênio adjacente ao anel tiadiazol. O mesmo pesquisador verificou que desde que o composto estava marcado no anel, este modo de degradą̧ão poderia não resultar na per da de ${ }^{14} \mathrm{C}$ da molécula.

O metabólito $c$ é o único dos três que exibe uma atividade herbicida significante mas é formada em quantidades pequenas.

Prosseguindo, o autor mostra a degradação microbiana de Tebutiuron comparando a taxa de degradação em so lo normal de laboratório com a degradação em solo fortificado com glicose e extrato de levedura para estimular a atividade microbiana. A taxa de degradação do Tebutiuron no solo fortificado foi notada por ser mais do que 2,5 vezes mais rá pida no solo de laboratório não fortificado. Essa degradação rápida foi atribuída ao aumento de atividade microbiana causada pela adição de nutrientes. O principal produto de degra dação detectado foi o metabólito demetilado. A presença desse metabólito em solo fortificado indicou que a $\mathrm{N}$-demetila ção do Tebutiuron foi um processo microbiano.

A meia-vida do Tebutiuron no solo foi de 10-13 meses em áreas com precipitação pluviométrica moderada a alta, como observou o mesmo autor.

Em experimentos que foram conduzidos em área com pouca precipitação (menos que $250 \mathrm{~mm} / \mathrm{ano}$ ) a taxa de dissipação foi muito vagarosa.

De acordo com pesquisadores dos Laboratórios 
21.

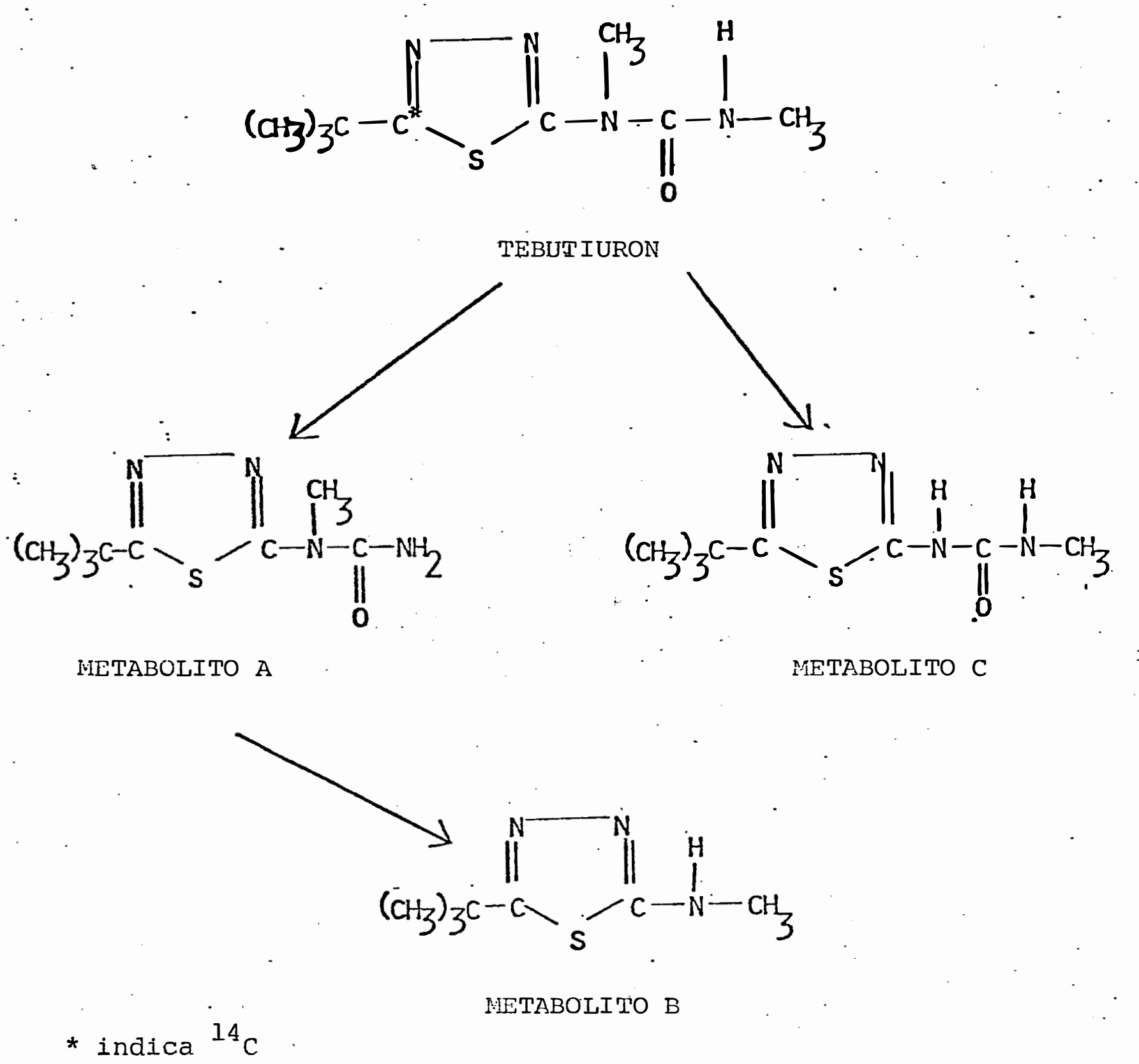

FIGURA 3 - DEGRADAÇÃO DE TEBUTIURON NO SOLO 
Lilly a taxa de dissipação foi proporcional a concentração de Tebutiuron no solo; indicando uma reação de la. ordem.

Ainda conforme esses pesquisadores Tebutiuron

lixivia-se lentamente quando exposto à chuva de moderadas a altas; com chuvas menores menos movimentos de Tebutiuron no solo são esperados; além disso muito pouco ou nenhum movimento lateral de Tebutiuron foi observado nesse experimento.

A Tabela 5 nos dá uma idéia da lixiviação de Tebutiuron em solo argilo-arenoso, com 1,98 de matéria orgâni ca e pH 7,2.

Tabela 5. Lixiviação do Tebutiuron em solo argilo-arenoso Profundidade \% da radioatividade ${ }^{14} \mathrm{C}$ aplicada, semanas do solo $(\mathrm{cm})$ após aplicação

\begin{tabular}{rrrrrr}
\hline & 0 & 4 & 14 & 51 & 64 \\
\cline { 2 - 6 } $0-8$ & 100 & 74 & 89 & 41 & 34 \\
$8-16$ & & 26 & 10 & 20 & 13 \\
$16-24$ & & & 1 & 10 & 5 \\
$24-32$ & & & & 6 & 4 \\
$32-40$ & & & & 4 & 3 \\
$40-48$ & & & & & 2
\end{tabular}

Chuvas acumuladas (mm)

FONTE: ANÔNIMO (1975)

2.3. INTERAÇÃO PRODUTO X GRAMINNEA

Poucos são os trabalhos efetuados no Brasil e em outros países que mostram a interação entre Tebutiuron e o capim colonião a não ser aqueles referentes ao desenvolvimento do produto para pastagem realizado pelos pesquisadores do Centro de Pesquisas Agronômicas da Elanco Química Ltda. Esses estudos, no entanto, visaram apenas de- 
terminar as doses adequadas a serem utilizadas em,..pastagens bem como a injúria provocada no capim e os efeitos sobre plan tas daninhas e principalmente os arbustos invasores: não foram estudados aspectos bioquímicos da ação de Tebutiuron sobre as gramíneas presentes nos experimentos.

Tal fato nos levou a pesquisar a ação do produto sobre outras gramíneas ou mesmo plantas dicotiledôneas para termos um ponto de apoio para basearmos nosso experimento. Estudando a absorção, translocação e metabolismo do Tebutiuron em cana-de-açucar, RAINEY et alii. (1976) verificaram que o produto é rapidamente absorvido através das raízes e translocado através do xilema para as outras partes da planta; Tebutiuron e mais quatro metabólitos foram notados quando da análise dos extratos e as principais alterações da cadeia lateral.

O mesmo caminho metabólico foi encontrado por MAGNUSSEN e RAINEY (1974) em estudos levados a efeito utilizando-se duas gramineas nativas, "indiangrass" (Sorghastrum nutans) e "little bluestem" (Schizachyrium scoparium) e Festu ca arundinácea, comumente semeada sobre pastagem após a remoção de plantas arbustivas.

A ação de Tebutiuron sobre a qualidade de forragens de gramineas selecionadas está sendo estudada por SOSEBEE (1979) que em suas avaliações preliminares verificou que as análises indicaram não haver significantes diferenças entre plantas tratadas e não tratadas em relação à quantidade de caroteno, clorofila a, clorofila b e teor de fósforo. Poucas diferenças foram notadas na quantidade de: carboidratos não-estruturais e teor de proteínas como resultado da aplicação de Tebutiuron. Notou entretanto que o conteúdo de água nas plantas tratadas foi significativamente maior do que em plantas não-tratadas, mas o esclarecimento para este fato necessita de estudos posteriores.

BAUR et alii, (1977) conduziram experimentos de 
campo para avaliar os efeitos de aplicação de vārios herbicidas, incluindo Tebutiuron, sobre a produção e niveis de proteína de algumas gramineas. As aplicações de Tebutiuron foram feitas em 3 épocas diferentes e os dados para Panicum coloratum são resumidamente apresentados nas Tabelas 6 e 7 .

\section{Tabela 6 .}

Produção de Panicum coloratum por intervalos durante os primeiros 100 dias após tratamento com três doses de Tebutiuron aplicado em três datas diferentes durante a primavera de 1974 e 1975. A precipitação é mostrada para o intervalo de crescimento amostrado.

\begin{tabular}{|c|c|c|c|c|c|c|}
\hline \multirow{3}{*}{ Produto } & \multirow{3}{*}{$\begin{array}{c}\text { dose } \\
(\mathrm{P.F.})\end{array}$} & \multirow{3}{*}{ 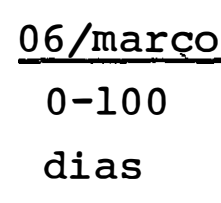 } & \multicolumn{2}{|c|}{ 01/abril } & \multicolumn{2}{|c|}{$05 / j$ unho } \\
\hline & & & $0-30$ & $30-100$ & $0-30$ & $30-100$ \\
\hline & & & dias & dias & dias & dias \\
\hline & $\mathrm{kg} / \mathrm{ha}$ & & $\mathrm{kg} / \mathrm{l}$ & a/dia & & \\
\hline \multirow[t]{3}{*}{ Tebutiuron } & 0,4 & 32 & 66 & 31 & 94 & 24 \\
\hline & 1,1 & 30 & 48 & 30 & 82 & 19 \\
\hline & 2,2 & 30 & 41 & 18 & 93 & 18 \\
\hline Controle & 0 & 39 & 46 & 17 & 94 & 38 \\
\hline Chuvas (mm) & & 361 & 64 & 86 & 36 & 422 \\
\hline
\end{tabular}

FONTE : BAUR (1977)

Pode-se verificar que 0 herbicida não teve efeito significante sobre a produção quando aplicado, no estado de dormência. Inibição da rebrota por 1,1 e 2,2 kg/ha de Tebutiuron foi aparente 6 meses após o tratamento feito em junho; entretanto, o capim teve completa recuperação um ano após 0 tratamento. Verifica-se também que Tebutiuron, aplicado na dose de $1,1 \mathrm{~kg} / \mathrm{ha}$ em junho, causou uma estimulação sịnificante no nivel de proteína na rebrota de Panicum coloratum; todavia não se tem explicações para essas alterações.

BONDINI e PETTIT (1979) mostraram, em resulta- 
Tabela $\nabla$. Concentração de proteína em Panicum coleratum em 2 intervalos durante os primeiros 100 dias após tratamento com três doses de Tebutiuron aplicado em 2 datas diferentes durante a primavera de 1974

\begin{tabular}{|c|c|c|c|c|c|}
\hline \multirow[b]{2}{*}{ Produto } & \multirow[b]{2}{*}{$\begin{array}{l}\text { dose } \\
(\text { P.F.) }\end{array}$} & \multicolumn{2}{|c|}{ 01/abril } & \multicolumn{2}{|c|}{ 05/junho } \\
\hline & & $\begin{array}{c}0-30 \\
\text { dias }\end{array}$ & $\begin{array}{c}30-100 \\
\text { dias }\end{array}$ & $\begin{array}{c}0-30 \\
\text { dias }\end{array}$ & $\begin{array}{c}30-100 \\
\text { dias }\end{array}$ \\
\hline & $\mathrm{kg} / \mathrm{ha}$ & & $-\mathrm{mg} / \mathrm{g}$ & peso seco & \\
\hline \multirow[t]{3}{*}{ Tebutiuron } & 0,4 & 7,7 & 13,4 & 13,3 & 10,9 \\
\hline & 1,1 & 6,1 & 13,1 & 15,7 & 16,5 \\
\hline & 2,2 & 8,5 & 14,3 & 17,5 & 10,0 \\
\hline Controle & 0 & 8,8 & 15,4 & 15,7 & 8,5 \\
\hline
\end{tabular}

FONTE: BAUR (1977)

dos preliminares que a produção de massa verde aumentou rapidamente quando foi controlado com Tebutiuron. Como o solo no qual cresceu a planta é um solo arenoso, altamente deficiente em nitrogênio e como a forragem não é usualmente pobre em pro teína, duas hipóteses foram aventadas: a) a decomposição do sistema radicular da planta é rāpida, permitindo ao nitrogênio ser reciclado $e$ b) o herbicida afeta diretamente as funções metabólicas e fisiológicas dentro da planta. Com a finalidade de testar os efeitos de baixas concentrações de Tebutiuron sobre a germinação, crescimento e conteúdo de proteína de várias espécies, incluindo Sorghastrum nutans, Eragrostis spp, Boutelona spp., foi iniciado um experimento em casa de vegetação. Trinta dias após plantio, $0,54 \mathrm{~kg} / \mathrm{ha}$ de Tebutiú ron, como uma suspensão, foi adicionado a todas as bandejas.

As plantas foram cortadas 20 dias após aplicação e verificou-se que os capins eram $46 \%$ menores e a biomassa foi $75 \%$ menor do que as plantas não tratadas. Todos os ca- 
pins tratados tiveram em média 428 mais proteína do que aqueles não tratados. Todavia os autores concluiram que mais ensaios são necessários para um completo entendimento dessas averiguações.

EATON e DECKER (1978) avaliaram os efeitos de Tebutiuron sobre qualidade e acumulação de matéria seca em 4 gramíneas forrageiras. As gramíneas avaliadas foram Andropogon gerardi, Leptochloa dubia, Festuca arundinacea e Beutelona curtipendula; essas espécies foram selecionadas porque foram adaptadas em várias regiões dos Estados Unidos e represen tam a principal porção do componente forrageiro em áreas onde Tebutiuron deve ser utilizado; esses capins têm bom a excelen te valor forrageiro, são palatáveis para gado e têm moderado a bom valor de pasto para animais silvestres. Após aplicarem Tebutiuron em pré-emergència, 2 e 4 semanas após o plantio os autores verificaram que o produto não afetou a produção de matéria-seca mas houve severa injúria de algumas gramíneas quando aplicado em pré-emergência.

Concluiram mostrando que Tebutiuron parece causar um leve decréscimo no conteúdo de proteína em algumas espécies de gramíneas, mas não afeta o conteúdo nutricional delas nem altera sua digestibilidade.

ROUQUETE (1978), trabalhando com Eragrostic curvula não observou diferenças na porcentagem de proteína e fibras (neutra e detergente) entre as amostras tratadas e con trole (as doses de Tebutiuron foram $0,5-1,0$ e 2,0 kg/ha).

SHROYER (1977) estudou o efeito de Tebutiuron

sobre o nível de carboidratos em raízes de Quercus marilandica e Ulmus alata, procurando achar uma relação entre o produto e as plantas. COOKE (1955) mostrou que monuron causa um decréscimo no conteúdo de carboidratos da parte aérea de algu mas plantas terrestres; WALSH e GROW (1971) relataram que diu ron, neburon, monuron e fenuron diminuiram os níveis de carbo idratos de seis espécies de algas marinhas. As conclusões a 
que chegou SHROYER em seu trabalho, após a aplicação de Tebú tiuron em dose equivalente a $2,24 \mathrm{~kg} / \mathrm{ha}$ foram:

a) o produto reduziu a quantidade de carboidratos não estruturais nas raízes tanto de Quercus. sp como de Ulmus, sp, com maior intensidade nesta última.

b) Um ano após o tratamento com Tebutiuron, ulmus alata esta va completamente defoliada enquanto houve uma defoliação par cial em Quercus marilandica.

A defoliação é uma das características da ação do produto sobre plantas arbustivas como atestam $\cdots$.'DUTRA : et alii (1980) em 11 experimentos realizados nos Estados de são Paulo, Mato Grosso, Minas Gerais e Goiás, em Capim còlonião (Panicum maximum). As tabelas 8, 9, 10 mostram a fitotoxicidade, a porcentagem de área coberta e o desempenho de Tebutiuron aplicado na pastagem.

Tabela 8. Fitotoxidade do Tebutiuron aplicado em Panicum maximum

\begin{tabular}{|c|c|c|c|c|}
\hline \multirow[t]{2}{*}{ Produto } & \multirow{2}{*}{$\begin{array}{l}\text { dose } \\
\mathrm{kg} / \mathrm{ha}\end{array}$} & \multicolumn{3}{|c|}{ Fitotoxidade $1 /$} \\
\hline & & $3 \longrightarrow 2 /$ & 6 & 12 \\
\hline Tebutiuron & 2,0 & 1,7 & 1,3 & 0 \\
\hline Tebutiuron & 4,0 & 3,3 & 2,4 & 0 \\
\hline Testemunha & 0,0 & 0 & 0 & 0 \\
\hline
\end{tabular}

FONTE: DUTRA (1980)

I/ Escala: $0=$ sem efeito tóxico; 10 = morte

2/ MAA: meses após aplicação

Segundo GARCIA e LEE (1979) espécies lenhosas têm defoliações por diversos anos seguindo-se a aplicação de Tebutiuron. Esses autores lançaram uma hipótese sobre o prová vel "Ciclo do Tebutiuron": Tebutiuron è absorvido pelas raízes em grande extensão de área e translocado para as. partes aéreas da planta acumulando-se aí até atingir uma concentra- 
Tabela 9. Porcentagem de superfície coberta por Panicum maximum após aplicação de Tebutiuron

\begin{tabular}{lcccc}
\hline Produto & $\begin{array}{r}\text { Dose } \\
\text { kg/ha }\end{array}$ & \% Superficie coberta & \\
\cline { 2 - 5 } & 3 & 69 & 62 & 12 \\
\hline Tebutiuron & 2,0 & 60 & 45 & 63 \\
Tebutiuron & 4,0 & 66 & 46 & 59 \\
Testemunhas & 0,0 & 28 \\
\hline
\end{tabular}

FONTE : DUTRA (1980)

I/ MAA = meses após aplicação

Tabela 10. Efeito do Tebutiuron no controle dos arbustos

\begin{tabular}{llc}
\hline Nome Cientifico & Nome Comum & \multicolumn{2}{c}{ Controle } \\
\cline { 3 - 3 } & & Tebutiuron $(1-4 \mathrm{~kg} / \mathrm{ha})$ \\
\hline Barnadesia rosea & Espinho-agulha & 100 \\
Pterocaulum virgatum & Branqueja & 80 \\
Peschiera fuchsiaefolia & Leiteiro & 100 \\
Randia armata & Roseta & 86 \\
Soliva sessilis & Limão-bravo & 93 \\
Vernonia polianthes. & Assa-peixe & 100 \\
\hline
\end{tabular}

FONTE: DUTRA (1980)

I/ Porcentagem dos arbustos mortos; 0 = nenhum arbusto morto: $100=100$ 으 da área em estudo com arbustos mortos.

ção excede a habilidade da planta para detoxificar o herbici da, o efeito deste torna-se visível, primeiro nas folhas e no vas extremidades.

A atividade fotossintētica è afetada e logo ocor re a defoliação. Folhas e hastes, contendo Tebutiuron e/ou seus metabólitos retornam à superfície do solo onde decompõemse e através do processo de lixiviação, voltam a tornar-se dis poníveis as plantas. GARCIA e LEE continuam a colher amostras de planta e solo para continuar a avaliar os efeitos de Tebu- 
tiuron e tarbém testar a hipótese ventilada. 


\section{MATERIAIS E MÉTODOS}

3.1. DATA: O teste foi iniciado no dia 01 de fevereiro de 1979 e teve a duração de 135 dias, termi nando portanto em 15 de junho de 1979 .

3.2. LOCAL: O experimento foi realizado na Estação Expẹ rimental da Elanco Química Lṫda, em Cosmópó lis, São Paulo; o solo onde foi instalado o ensaio é um solo areno-argiloso.

3.3. MATERIAL EXPERIMENTAL:

Nome Genérico: Tebutiuron

Nome Químico: $\mathrm{N}-[5-(1,1-$ dimetiletil $)-$ $1,3,4$ - tiadiazol 2 - il $]-N$, N' - dimetiluréia

Nome Comercial: GRASLAN 20 PELETIZADO

Classe: Herbicida pertencente a classe das uréias substituídas.

Formulação: Grânulos

Concentração: Cada grânulo contēm $20 \%$ de in grediente ativo Tebutiuron.

Graminea: A gramínea presente na área era - capim-colonião, Panicum maxi mum, Jacq.

3.4. CONCENTRAÇOẼS: Tebutiuron foi aplicado nas doses de 
0,0 (testemunha) $-1,2 \mathrm{~kg} / \mathrm{ha}-2,4 \mathrm{~kg} /$ ha e $4,8 \mathrm{~kg} / \mathrm{ha}$, correspondendo a 0,0 - 6,0 - 12,0 e $24,0 \mathrm{~kg} / \mathrm{ha}$ de produto formulado GRASLAN $20 \mathrm{P}$.

3.5. PREPARO DO LOCAL: Foi escolhida uma área de $300 \mathrm{~m}^{2}$ onde nunca havia sido aplicado o produto; nesta área o capim-colonião já estava estabelecido, tomando toda a área de experimento. A área toda foi cortada, através de roçadeira mecânica a uma altura de $5 \mathrm{~cm}$ do solo. Logo após, a parte central da área escolhí da foi dividida em 16 parcelas de $10 \mathrm{~m}^{2}(2 \mathrm{~m} \times 5 \mathrm{~m})$ cada, com uma separação entre uma parcela e outra de 0,5m. A seguir a área foi estaqueada para demarcação das parcelas.

3.6. ANĀLISE

ESTATISTICA: Os dados foram analisados de acordo com o esquema de parcelas subdivididas onde 4 tratamentos (doses) aplica dos às parcelas foram dispostos em quadrado latino, enquanto que as subparcelas foram consideradas os 3 cortes sucessivos, conforme ilustrado em PIMENTEL GOMES (1970). As comparações entre médias foram analisadas pelo teste de Tukey, enquanto que as compa rações entre cortes foram feitas atra vés de regressão polinomial.

3.7. DISTRIBUIÇÃO DOS GRÂNULOS: Após o estaqueamento das parcelas, os grânulos foram distribuídos manualmen te, ficando o aplicador no centro de 


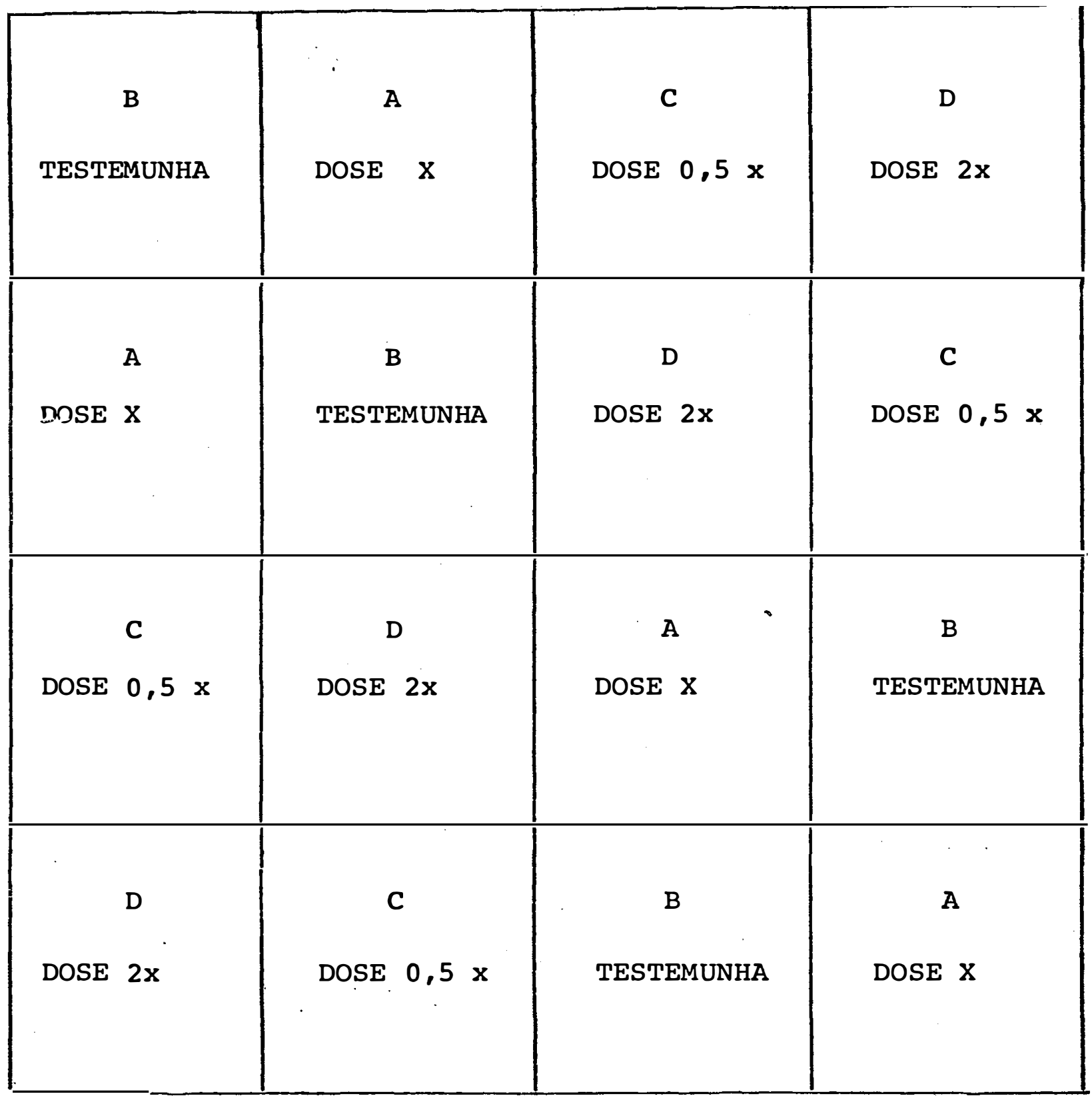

FIG. 4 Distribuição das parcelas no campo. Cada parcela media $(2 \mathrm{~m} \times 5 \mathrm{~m}) \cdot 10 \mathrm{~m}^{2}$ de área e entre cada uma havia um espá çamento de $0,5 \mathrm{~m}$. 
cada parcela. As parcelas controle re ceberam $10 \mathrm{~g} / 10 \mathrm{~m}^{2}$ de grânulos que não continham Tebutiuron; foram as parcelas controle. As parcelas tratadas à dose de $1,2 \mathrm{~kg} / \mathrm{ha}$ de Tebutiuron recebe ram $6 \mathrm{~g} / 10 \mathrm{~m}^{2}$ de GRASLAN $20 \mathrm{P}$.

As parcelas tratadas com a dose de $2,4 \mathrm{~kg} / \mathrm{ha}$ de Tebutiuron receberam 12 $\mathrm{g} / 10 \mathrm{~m}^{2}$ de GRASLAN $20 \mathrm{P}$.

As parcelas tratadas com a dose de $4,8 \mathrm{~kg} / \mathrm{ha}$ de Tebutiuron receberam 24g/ $10 \mathrm{~m}^{2}$, de GRASLAN $20 \mathrm{P}$.

Os grânulos foram pesados previamente e estavam colocados separadamente em sacos plásticos rotulados. A aplicação dos grânulos foi feita às 10 horas da manhã do dia 01 de fevereiro de 1979.

3.8. PLANTAS DANINHAS

PRESENTES NA

ÁREA DO ENSAIO: Antes de se proceder ao roçamento do capim-colonião, foi feito um levan tamento das plantas daninhas presentes na área do ensaio, que eram as se guintes:

Nome Científico Nome Comum

Rhÿnchelitrum roseum

Capim-favorito

Amaranthus spinosus

Caruru

Sida rhombifolia $\mathrm{L}$.

Guanxuma

Emilia sonchifolia DC Serralha

Ageratum conyzoides I Mentrasto

Bidens pilosa

Picão-preto

Erechtites hieracifolia Amargoso 
Nome Cientifico

Nome Comum

Erigeron bonariensis, Buva

Ipomoea purpurea lam. Corda-de-viola

As duas primeiras plantas daninhas eram as mais frequentes.

3.9. TEMPERATURA E CHUVA:

Durante todo o periodo do experimento foram anotadas a temperatura (diariamente) e a quantidade de chuva (ver Apêndice B)

3.10. TEMPO E ALTURA

DOS CORTES: Foram realizados três cortes, a cada intervalo de 45 dias; a altura dos cortes foi a $5 \mathrm{~cm}$ do solo; esta altura foi determinada levando-se em consideração o fato dos animais ao se alimentarem, cortarem o capim a essa altura.

\subsection{DETERMINAÇÕES}

E AMOSTRAGEM: A cada 45 dias os capins eram cortados (toda a área de $10 \mathrm{~m}^{2}$ ) com equipamento manual (foice). Uma balança era previamente instalada no local do ensaio sendo as pesagens feitas parcela por parcela. Eram separados $500 \mathrm{~g}$ de cada amostra que eram coloca das em sacos plásticos rotulados, que eram armazenados em isopor contendo gelo seco $\left(\mathrm{Ca} .20^{\circ} \mathrm{C}\right)$. Quatro a cinco gramas de matéria verde de cada parce la eram pesados na balança do Labora- 
tōrio de Resíduos da Elanco Química Ltda., situado a 500 metros do local do experimento, para se determinar a matéria-seca. Isto era feito secandose o material em estufa a $60-80^{\circ} \mathrm{C}$ até peso constante, (Método do A.O.A. c. $(1960)$.

A determinação de carboidratos solūveis era feita imediatamente após, com o material fresco; essa determina ção foi feita através do método de DUBOIS et alii, (1956) fazendo-se a leitura no colorimetro klett-Summerson, a 650 nanometros. Deve-se observar que decorreram 4 horas entre a amostragem e a determinação.

Para a determinação de proteínas as amostras eram preparadas secando-se uma certa quantidade de capim-colonião em estufa a $80-100^{\circ} \mathrm{C}$ até peso constante; a seguir as amostras passaram em moinho de laboratório (Wiley Mill) e depois foram transferidas para frascos de vidro rotulados, para serem analisadas. 0 teor de proteína foi determinado pelo método de Kjehdàl, verificando-se a quantidade de nitrogênio e multiplicando-se por 6,25 (A.O.A.C. 1960). Para se determinar a eficiência da ação herbicida sobre as plantas dani nhas, bem como a injúria provocada pelo produto no capim foram feitas 2 avaliações, uma aos 30 dias e a ou- 
tra aos 100 dias Foi utilizada uma escala que variava de 0 a 10, para se determinar a injūria causada pelo produto no capim, sendo $0=$ ausência de injúria e 10 = morte do capim. Para se determinar a eficiência da ação herbicida utilizou-se a mesma escala, sendo que 0 valor $0=$ nenhum controle e $10=100 \%$ de controle. Foi feita também uma avaliação da superfície de área coberta pelo capim-colonião para se verificar se houve ou não redução do "stand". 


\section{RESULTADOS E DISCUSSÃO}

4.1. PORCENTAGEM DE MATERIA SECA:

Na Tabela 11 estão apresentadas as médiás de porcentagem de Matéria Seca por tratamento e por corte e na Tabela 12 a análise de variância correspondente.

Tabela 11. Porcentagem de Matéria Seca por tratamento e por corte; média de 4 repetições

\begin{tabular}{cccc}
\hline TRATAMENTO & \multicolumn{4}{c}{ DIAS } \\
\cline { 2 - 4 }$(\mathrm{kg} / \mathrm{ha})$ & 45 & 90 & 135 \\
& $(19$ Corte) & $(29$ Corte) & $(39$ Corte) \\
\hline 0,0 & 16,91 & 21,10 & 28,71 \\
1,2 & 15,40 & 18,83 & 29,74 \\
2,4 & 17,97 & 21,07 & 29,69 \\
4,8 & 16,67 & 19,21 & 29,71 \\
\hline
\end{tabular}

Os resultados obtidos mostram que não houve efei to significativo $(\langle 5 \%)$ das doses de Tebutiuron aplicadas so bre o teor de matéria-seca. Por outro lado houve variação estatisticamente significante entre os teores de matéria seca nos diversos cortes; o desdobramento dessa variação nos indicou haver uma resposta entre o teor de matéria seca e os cortes que obedecem a equação quadrática. 
Tabela 12. Análise de variância para matéria sêca.

Causas de

\begin{tabular}{lcrrr} 
Variação & G.L. & SQ & QM & F \\
\hline Linhas & 3 & 13,830825 & 4,610275 & \\
Colunas & 3 & 5,302942 & 1,767647 & \\
Doses (D) & 3 & 15,973525 & 1,324508 & 2,34 (n.s.) \\
Residuo (a) & 6 & 13,672225 & 2,278704 &
\end{tabular}

Parcelas $\quad 15 \quad 48,779517$

\begin{tabular}{lcccc}
\hline Cortes (C) & $(2)$ & $(1393,868281)$ & $(696,934141)$ & $(286,55)$ * \\
Linear & 1 & 1294,641613 & 1294,641613 & 532,31 * \\
Quadrática & 1 & 99,226667 & 99,226667 & 40,80 * \\
D x C & 6 & 17,680319 & 2,946720 & 1,21 n.s. \\
Resíduo (b) & 24 & 58,371331 & 2,432139 &
\end{tabular}
C.V. Parcelas $=6,848$
C.v. Sub-parcelas $=7,068$

Atravēs do coeficiente de determinação $\left(r^{2}\right)$ verificou-se que o componente linear foi responsável por 92,98 da variação enquanto o componente quadrático representou apenas 7,18 dessa variação.

Essa resposta encontrada para o teor de matéria secạ, em função dos cortes, já era um resultado esperado e vem comprovar os dados encontrados por BOSE (1971); a conclusão que se pode obter desses dados é que houve uma elevação normal no teor de mațéria séca de.capim-colonião devido à idade e esta elevação não foi influenciada pelas doses do produto aplicado. 
39.

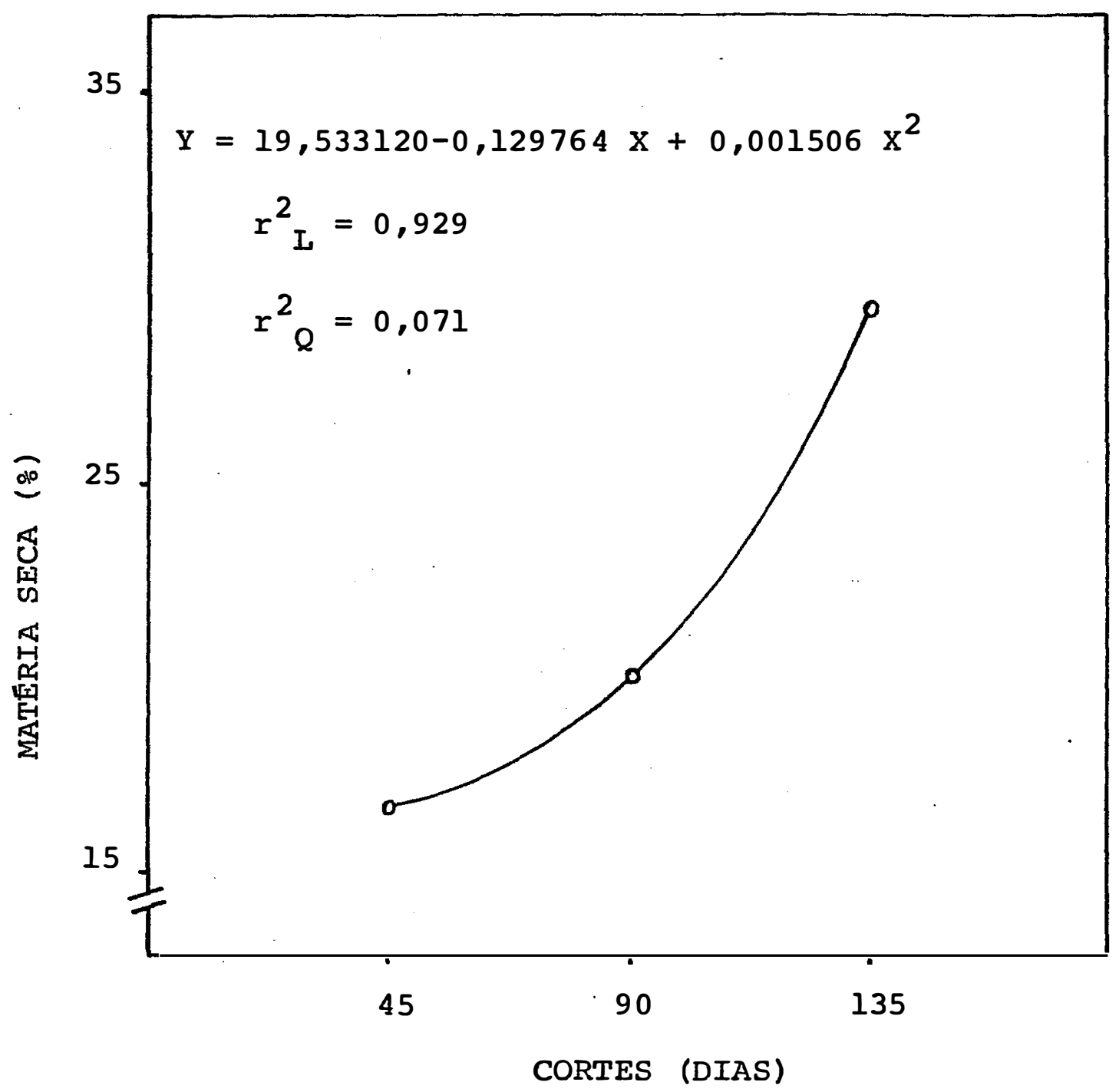

FIG. 5 Variação do teor de matéria seca em $\underline{\text { P. maximum em }}$ cortes sucessivos 
4.2. PORCENTAGEM DE CARBOIDRATOS SOLŨVEIS NA MATÉRIA SECA A Tabela 13 apresenta as médias de porcentagem' de carboidratos solúveis na matéria seca por tratamento e por corte e a Tabela 14 mostra a análise de variân cia correspondente.

Tabela 13. Porcentagem de carboidratos solúveis na matéria se ca, por tratamento e por corte; média de 4 reparti ções.

\begin{tabular}{lccc}
\hline \multirow{2}{*}{$\begin{array}{c}\text { TRATAMENTOS } \\
\mathrm{kg} / \mathrm{ha}\end{array}$} & \multicolumn{3}{c}{ DIAS } \\
\cline { 2 - 4 } & $(19$ Corte) & 90 & 135 \\
\hline & $(29$ Corte) & (39 Corte) \\
0,0 (Test.) & 11,53 & 5,68 & 6,02 \\
1,2 & 9,54 & 7,70 & 5,18 \\
2,4 & 10,13 & 5,55 & 5,32 \\
4,8 & 10,13 & 7,44 & 5,15 \\
\hline
\end{tabular}

Se formos atentar para o fato de que KEANEY e KENNEDY (1962) e JOHNSON et alii. (1966) indicam ser necessário um teor mínimo de $15 \%$ de carboidratos solúveis na matéria seca para que haja uma boa fermentação no ato de ensilagem, os valo res encontrados para carboidratos solúveis no Panicum maximum, neste estudo deixam muito a desejar; PUPO ( 1980) indica um mínimo de $12 \%$ e um ideal de $15 \%$ de carboidratos solúveis para que uma forrageira produza silagem de alta qualidade.

Não houve uma resposta dos teores de carboidratos solúveis às doses aplicadas como indicado pela Tabela 14, nem uma interação entre doses e cortes, mas houve um decreści- 
Tabela 14. Análise de variância da porcentagem de carboidratos solúveis

Causas de

Variação

G.L:

SQ

$Q M$

F

\begin{tabular}{lrrrr}
\hline Linhas & 3 & 32,189250 & 10,729750 & 2,06 n.s. \\
Colunas & 3 & 5,996183 & 1,998728 & 0,38 n.s. \\
Doses (D) & 3 & 4,314417 & 1,438139 & 0,28 n.s. \\
Resíduos (a) & 6 & 31,185283 & 5,197547 & \\
\hline
\end{tabular}

Parcelas

15

73,685133

Cortes (C)

(2)

$(233,481979)$

$(116,740990)$

Linear

$1 \quad 215,800313$

$215,80031322,60$ **

Quadrātica

$1 \quad 17,681557$

17,681667

i, $85 \mathrm{~ns}$

D $\times$ C

6

22,138821

3,689804

$0,39 \mathrm{~ns}$

Resíduo (b)

$24 \quad 229,117934$

9,546581

CV Parcelas $=30,048$

CV Sub-parcelas $=40,718$

mo altamente significativo nos teores de carboidratos solúveis do 18 para 038 cortes; esse decréscimo obedece uma equação li. near.representada graficamente na Figura 6 .

Esses dados são semelhantes àqueles obtidos por SHROYER (1977), trabalhando com carboidratos não estruturais; COOKE (1955) e WALSH e GROW (77), como mostrado anteriormente também verificaram um decréscimo nos níveis de carboidratos de plantas e algas após administração de herbicidas derivados da uréia; desde que CHANG e STRITZKE (1977) e STEINERT e STRITZKE 
(1977) mostraram que a adsorção, o movimento e a dissipação no solo, a retirada pelas raízes e a translocação de 'Tebutiuron são muito semelhantes ao que ocorre com outros herbicidas derí vados na uréia, pode-se supor que haja alguma relação entre a aplicação do produto e o decréscimo no teor de carboidratos so lúveis. Todavia esse aspecto é bastante discutível uma vez que a maior redução no teor de carboidratos ocorreu na parcela tes temunha, que não recebeu o produto.

PETERSON (1970) mostra ser o hábito de crescimento de grande importância na resposta ao corte, pois cortando-se uma planta "pequena" a uma determinada altura, a diminui ção na folhagem e consequentemente na capacidade de fotossíntese não será tão grande quanto numa planta "maior",que é o ca so do Capim-colonião; isto porque a redução na relação de área foliar é maior numa planta de maior porte do que uma de porte pequeno. Outro fator citado por PETERSON (1970) é em relação a rapidez de crescimento; se os cortes se fizerem em intervalos curtos, aquelas que crescem rápido são mais afetadas do que as que rebrotam lentamente, pois esgotam em pouco tempo suas reservas.

O intervalo entre os cortes, de 45 dias, é um intervalo normal dentro do período mais quente do ano, onde as temperaturas são elevadas e há boa distribuição de chuvas; durante o outono a temperatura, como indicada no Apêndice B caiu bastante e nessas condições o corte, para obtenção de uma produção razoável, deveria ser realizado num período maior, o que não foi realizado face aos objetivos propostos neste trabalho. PUPO (1980) mostra ser o Capim-colonião: pobre em carboidratos fermentescíveis, recomendando a colocação de aditivos para corrigir essas deficiências quando esta gramínea vai ser ensilada.

Outro fator a ser considerado nesta discussão é o período de tempo decorrido entre a amostragem e a determinação dos carboidratos solúveis, pois os açucares são prontamen- 
43.

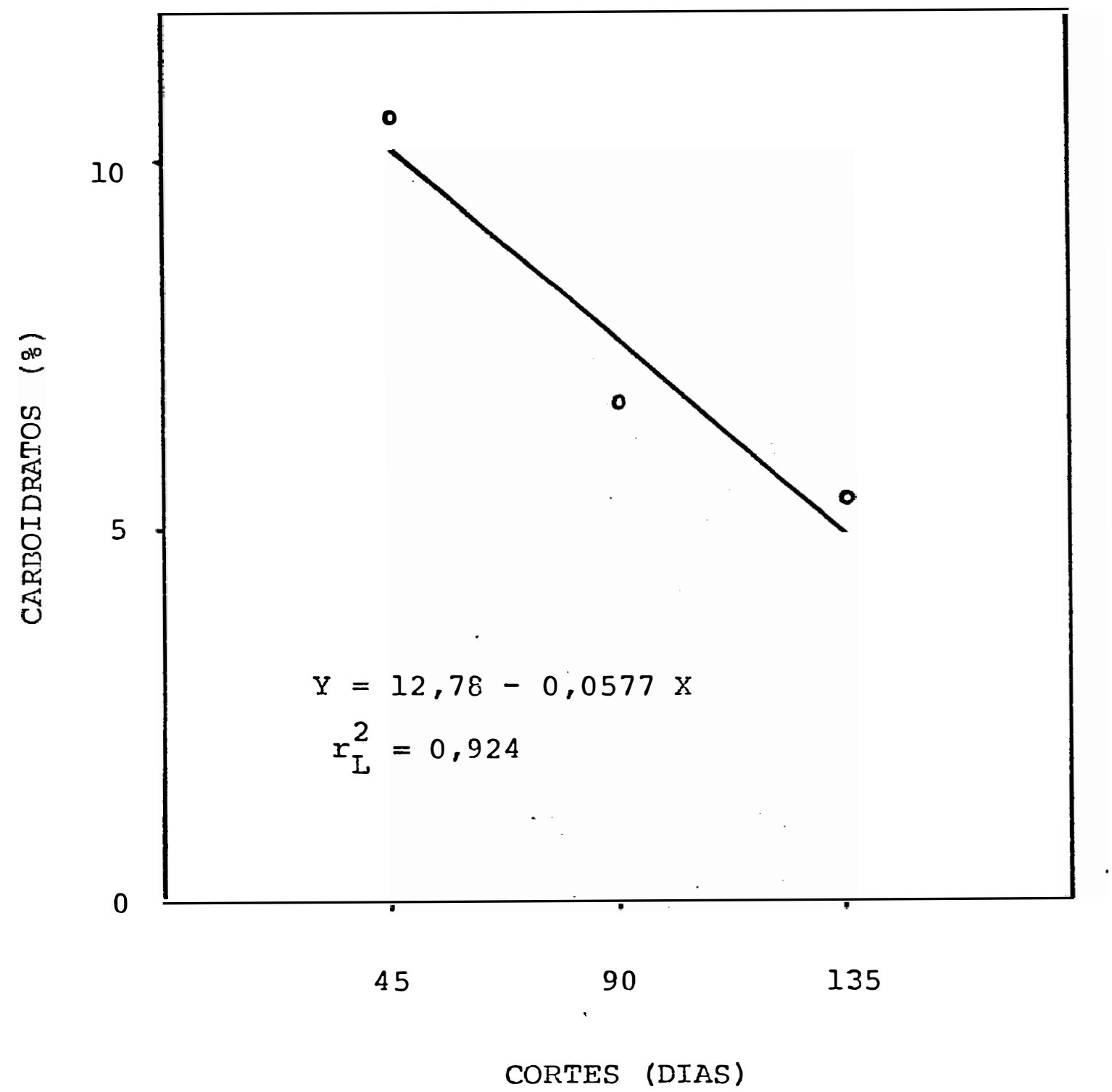

FIG 6 Variação do teor de carboidratos em relação à matéria seca em $\underline{P}$. maximum 
te utilizados para o metabolismo respiratório.

Isto nos leva a concluir que a diminuição nos teores de carboidratos solúveis está mais relacionada ao efeito de corte e hábito de crescimento do Capim-colonião do : que numa possível influência do produto sobre a planta; como a interação entre doses e cortes não foi significativa, concluímos que a redução no teor de carboidratos solúveis no Capim - còlonião foi idêntico em todas as doses testadas.

\subsection{PORCENTAGEM DE PROTEINA NA MATÉRIA SECA}

A análise de variância apresentada na Tabela 16 mostrou que houve uma influência das doses aplicadas no teor de proteína na matéria seca.

A porcentagem de proteína obtida nas parcelas que receberam a dose mais elevada do Tebutiuron $(4,8 \mathrm{~kg} / \mathrm{ha})$ foi significativamente $(P<0,05)$ superior às porcentagens de proteína nas demais parcelas e que estas não diferiram entre si. Há portanto uma tendência para um aumento no teor de proteína com $\circ$ aumento da dose aplicada. Apesar dessa tendência mostrada pela análise estatística, é difícil obter-se uma resposta para o fenômeno uma vez que, conforme visto na revisão de lite ratura, o teor de proteína cresce, decresce ou mantém-se inalterado de acordo com a espécie de planta estudada. FREED(1952) fez menção a um possível efeito dos herbicidas-uréia sobre o metabolismo do nitrogênio mas a falta de dados não permitiu uma averiguação melhor, mesmo ocorrendo com outros pesquisadores que verificaram haver alteração no teor de proteína mas não tinha uma explicação para a ocorrência.

Uma possível especulação para o fato de FREED (1952) ter mencionado uma ação de herbicida-uréia sobre o ciclo do nitrogênio seria uma influência do produto sobre a atividade da enzima, redutase de nitrato (EC.1.6.6.2), que catalisa a redução de nitrato até nitrito, sendo que os nitratos 
Tabela 15. Porcentagem de proteína na matéria seca, com os da dos representando a média de 4 repetições.

TRATAMENTOS

$\mathrm{kg} / \mathrm{ha}$
DIAS

$\begin{array}{ccc}45 & 90 & 135 \\ \text { (18 Corte) } & \text { (28 Corte) } & \text { (38 Corte) }\end{array}$

$\begin{array}{llll}0,0 \text { (Test.) } & 14,08 & 11,68 & 12,09 \\ 1,2 & 14,30 & 12,20 & 12,58 \\ 2,4 & 14,30 & 11,87 & 13,01 \\ 4,8 & 17,42 & 16,06 & 13,60\end{array}$

constituem a principal fonte de nitrogênio disponível no solo e para que possa ser utilizado deve ser reduzido à amônia; es sa redução à amônia envolve na primeira fase a redução de nítrato para nitrito, como mostra o esquema da Figura 7, de acordo com CROCOMO (1967); GUTIERREZ (1977) mostra os diversos fatores que influenciam a atividade dessa enzima; este fato nos indica um ponto de partida para futuras investigaçōes.

Foi também observado um efeito linear significativo sobre o teor de proteína, representado graficamente na $F \underline{\underline{i}}$ gura 8 , mas estes resultados não diferem daqueles obtidos por BOSE (1971), e já erám esperados.

A conclusão a que se pode chegar é que há uma tendência para um acréscimo no teor de proteína na matéria seca com a aplicação de doses elevadas; o que se deve determinar porém é a partir de que dose esse acréscimo começa a ser signi ficativo. Deve-se ressaltar que no 38 corte o teor de proteína praticamente não diferiu entre todas as parcelas. 
Tabela 16. Análise de variância da porcentagem de proteína do Capim-colonião

Causas de

Variação

G.L.

SQ

QM

$\mathbf{F}$

\begin{tabular}{lrrrr}
\hline Linhas & 3 & 17,138156 & 5,712719 & \\
Colunas & 3 & 7,196873 & 2,398958 & \\
Doses (D) & 3 & 71,673456 & 23,891152 & $7,14 *$ \\
Resíduo (a) & 6 & 20,071146 & 3,345191 & \\
\hline
\end{tabular}

Parcelas (c)

$15 \quad 116,079631$

\begin{tabular}{lcccc} 
Cortes (c) & $(2)$ & $(48,774429)$ & $(24,387215)$ & \\
Linear & 1 & 38,764013 & 38,764013 & $12,47 \star \star$ \\
Quadrática & 1 & 10,010417 & 10,010417 & $3,22 \mathrm{~ns}$ \\
D x C & 6 & 16,184237 & 2,697373 & $0,87 \mathrm{~ns}$ \\
Resíduo & 24 & 74,610600 & 3,108775 & \\
\hline
\end{tabular}

$\mathrm{CV}$ parcelas $=13,45 \%$

CV sub-parcelas $=12,96 \%$ 


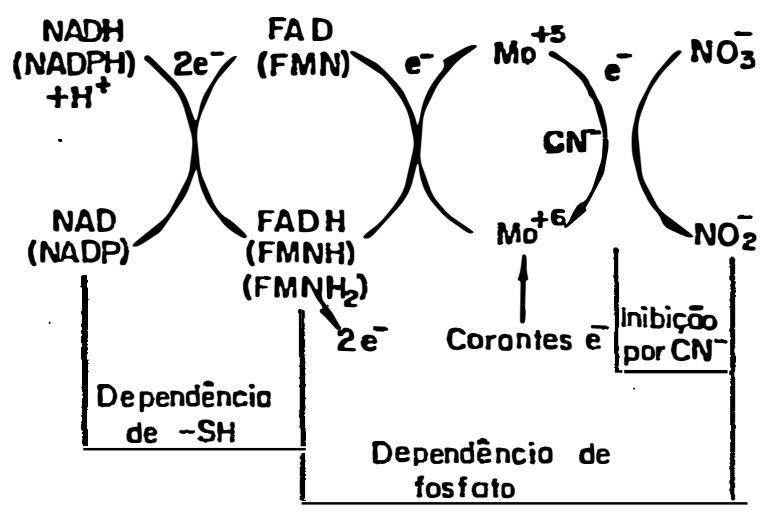

FIG. 7 Mecanismo geral da ação da redutase de nitrato (CROCOMO - 1967)

Estudos bioquímicos devem ser realizados para se tentar obter uma possível resposta para a variação do teor de proteína com doses elevadas de Tebutiuron. 
48.

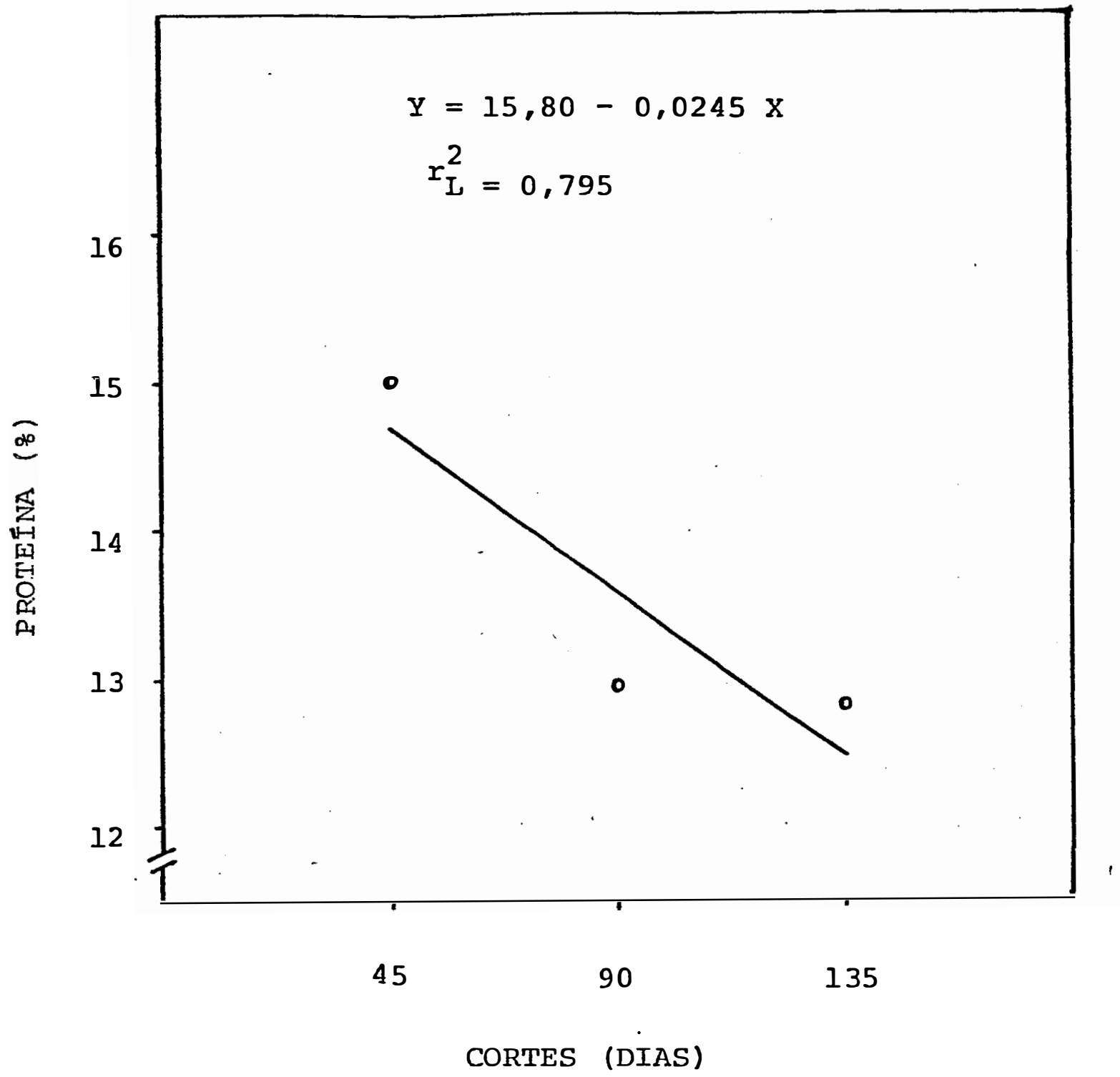

FIG. 8 Variação do teor de proteína na matēria seca, em ' $\underline{\text {. }}$ maximum 


\subsection{AVALIAÇÃO DO DESEMPENHO DE TEBUTIURON COMO HERBICIDA}

Os resultados apresentados na Tabela 17 indica ram ser. a dose $2,4 \mathrm{~kg} / \mathrm{ha}$ de Tebutiuron a que teve melhor desem penho, controlando as plantas daninhas e provocando leve injūria na cultura, apenas no primeiro mês de condução do experimento, Na dose de 4,8 kg/ha, o produto apesar de ter controlado as plantas daninhas causou uma injūria de moderada a alta no Capim-colonião, prōduzindo amarelecimento nas folhas e uma redução no "stand"; todavia, na segunda avaliação tanto o "stand" como a injúria provocada já mostravam sinais de reacão, com as parcelas apresentando um aspecto bastante semelhan te àquelas onde foram aplicadas doses menores; esses dados vêm comprovar o que um grande número de experimentos realizados no Brasil e no Exterior têm mostrado quanto à ação, a eficácia e o desempenho de Tebutiuron.

A elevada temperatura e a precipitação ocorrida (t $100 \mathrm{~mm}$ ) nos primeiros dez dias apōs o início do . experimento, proporcionaram ótimas condições para uma rápida ação do produto, o que foi notado pelo amarelecimento da grande maioria das plantas daninhas presentes, principalmente nas doses mais altas; apenas o capim favorito, Rhynchelitrum roseum não sofreu injúrias mais severas, comportando-se de modo semelhante ao capim-colonião.

Aos 100 dias praticamente todas as plantas dani nhas, com exceção do capim-favorito estavam bastante lesionadas, apresentando tecidos necrosados; houve uma recuperação do capim-colonião nas parcelas que receberam a dose mais elevada, com o capim cobrindo uma área maior. As parcelas testemunhas e as que receberam doses de 1,2 e 2,4 kg/ha de Tebutiuron tinham praticamente o mesmo aspecto.

Quinze meses após o final do experimento, houve

reforma da área do experimento, com o plantio de milho (Zea mays): não ocorreu nenhum problema quanto a derminação e cres- 


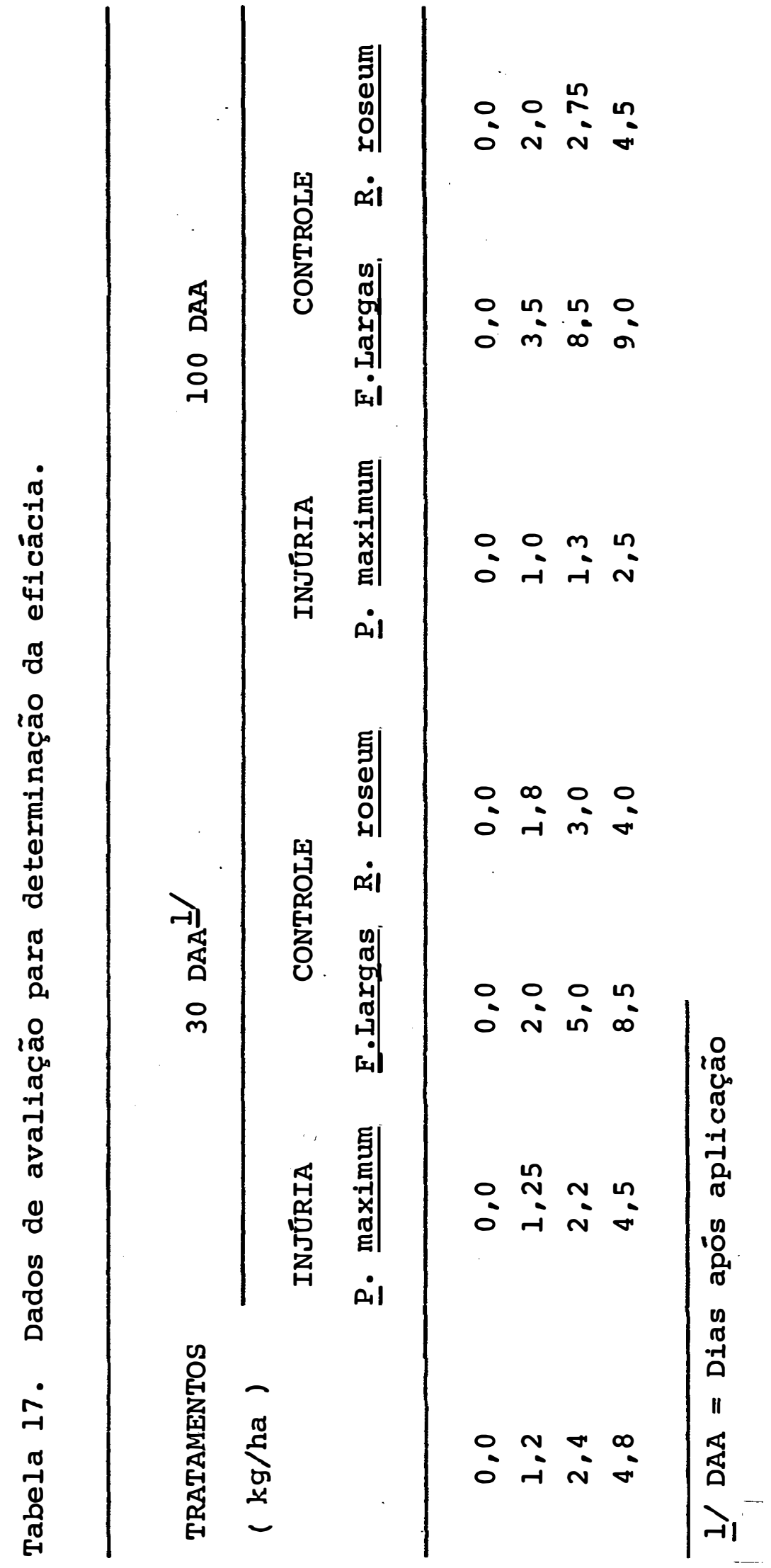


cimento dessa cultura demonstrando que mesmo com uma possível residualidade do produto, esta não foi suficiente para provo car injūria no milho ou mesmo uma redução na germinação. 
5. CONCLUSÕES

a. A dose de $2,4 \mathrm{~kg} / \mathrm{ha}$ de Tebutiuron, que corresponde a 12,0 $\mathrm{kg} / \mathrm{ha}$ do produto GRASLAN 20 PELETIZADO foi a que melhor de sempenho obteve, levando-se em consideração o controle das plantas daninhas e a injúria na cultura.

b. A dose de $4,8 \mathrm{~kg} / \mathrm{ha}$ de Tebutiuron provocou injúria no Capim colonião, que recuperou-se ao final do período do expe rimento.

c. O capim favorito, Rhynchelitrum roseum não foi controlado satisfatoriamente por Tebutiuron nas doses aplicadas.

d. Não houve influência do Tebutiuron sobre o teor de matéria seca no capim colonião, em nenhum dos níveis de tratamento.

e. Apesar dos teores de carboidratos solúveis na matéria seca terem sido baixos, não houve efeito do Tebutiuron sobre eles.

f. A dose de $4,8 \mathrm{~kg} / \mathrm{ha}$ de Tebutiuron provocou um acréscimo no teor de proteína na matéria-seca do capim-colonião. Esse aumento tende a diminuir com os cortes. Os demais tratamentos $(0,0-1,2$ e $2,4 \mathrm{~kg} / \mathrm{ha}$ de Tebutiuron) não produzi 
53.

ram efeitos significativos sobre o teor de proteínas. 


\section{IITERATURA CITADA}

AGROCERES, 1978. Pastagens melhoradas - Alternativa para um rebanho mais produtivo. Livreto técnico-informativo sementes Agroceres S/A.

ANÔNIMO, 1975. Behavior of Tebuthiuron in soil. Lilly Re search Laboratories. Indianápolis, Indiana, U.S.A. • Mimeografado $7 \mathrm{p}$.

A.O.A.C., 1960. Official and tentative methods of analysis. 9 yh. ed. Washington D.C. 832 p.

ASHTON, F. M. e A.S. CRAFTS, 1973. Mode of action of herbici des. New York. A Wiley Interscience Publication, 504p.

BAUR, J. R., R. W. BOWEY e E.C. HOLT, 1977. Effect of herbicides on production and protein levels in pasture grasses. Agron. J. 69 , : 846 - 851 .

BAUR, J.R., 1978. Movement in soil of Tebuthiuron from sprays and granules. Texas Agric. Exp. Stn. Prog. Rep. 3524: $1-14$. 
BIONDINI, M. e R.D. PETTIT, 1979. Graslan affects protein content of grass seedlings. Nox. Brush Weed Contr. Res. Highlights $\mathrm{P} 31$.

BOSE, M.L.V., 1971. Composição em fibra bruta, celulose e lignina, digestibilidade da celulose "in vitro" e em CED, dos capins colonião, gordura, jaraguá, napier e pangola, em desenvolvimento vegetativo. Tese de Doutora mento. Escola Superior de Agricultura "Luiz de Queiroz", Piracicaba, S,P.

BOWEN, J.E., 1967. Influence of Environmental Factors on the Efficacy of Preemerge Diuron Applications. Weed Science. 15,317 .

BOWES, G.G., 1977. Tolerance of bromegrass to Tebuthiuron. Res. Rep. Can. Weed Comm. West. Sect. 24 (pt2) : $21-22$.

BRODIE, B.B., J.R. GILLETTE e B.N. IA DU, 1958. Enzymatic metabolism of drugs and other foreign compounds. Ann Rev. Biochem. 27, 427.

CHANG, S.S. e J.F. STRITZKE, 1977. Sorption, movement and dissipation of Tebuthiuron in soils. Weed Science, 25 (2) : $184-187$.

COOKE, A.R., 1955. Effect of CMU on the biochemical composition of several legumes. North Central Weed Control Conf. Res. Rept. p 181 - 182.

COOKE, A.R., 1956. A possible mechanism of action of the urea type herbicide. Weeds, 4 : 397 - 398.

CRAFTS, A.S., 1959. Further studies on comparative mobility of labeled herbicide. Plant Physiol, 34 : 613:620. 
CRAFTS, A.S. e H.R. DREVER, 1960. Some experiments

with herbicides in soils. Weeds, $8,12-17$.

CROCOMO, O.J., 1967. Transformações metabólicas em microorganismos. Curitiba, $\operatorname{Pr}$. Instituto de Bioquímica da Universidade Federal do Paraná, 165 p.

DOROUGH, H.W. e J.E. CASIDA, 1964. Nature of certain carbamate metabolites of the insecticide sevin. J. Agric. Food. Chem. 12 : 294 .

DOWNTON, W.J.S., 1970. Adaptive and evolutionary aspects of $\mathrm{C}_{4}$ photosynthesis. In Photosynthesis and photores pira tion. U.S.A. John Wiley and Sons, Inc.

DOWNTON, W.J.S., 1975. The occurrence of $\mathrm{C}_{4}$ photosynthesis among plants. Photosynthetica 9 (1) : 96 - 105.

DUBOIS, M., K.A. GILLES, J.K. HAMILTON, P.A. ROBERS P F.SMITH, 1956. Colorimetric method for determination of sugars and related substances. Anal. Shem. 28: 350 - 354 .

DUTRA, T.S., M. HING M.W., A.T. MELLO FO, P.R. MACHADO e S.A. SILVA, 1980. Tebutiuron Peletizado no controle de plantas invasoras nas pastagens. A Anais do. XIII Congresso Brasileiro de Herbicidas e Ervas Daninhas. Itabuna, Ba.

EATON, B.J. e O.D. DECKER, 1978. Effects of Tebuthiuron on quality and dry matter accumulation of four forage grasses. Lilly Research Laboratories. Indianapolis, Indiana, U.S.A.

EL - SHARKAWY, M.A., R.S. LOOMIS e W.A. WILLIANS, 1967. Apparent reassimilation of respiratory carbon dioxide by 
different plant species. Plant Physiol., 20: 171.

ELANCO QUIMICA LTDA, 1978. Pastagens no Brasil, Divisão de Marketing. Mimeografado. 100p.

FREED, V.H., 1952. IPC and Chloro-IPC on representative carba mates as herbicide. Am. Chem. Soc. 21;7

FURLAN, R.S., 1969. Influência da frequência e intensidade de corte no capim colonião (Panicum maximum. Jacq). Tese de Doutoramento. Escola Superior de Agricultura "Luiz de Queiroz". Piracicaba, S.P., 105p.

GARCIA, J.D. e S.C. LEE, 1979. A hypothesis on the cycling of Tebuthiuron. Nox Brush Weed Contr. Highlights, p. 39-40.

GEISBUHLER, H., H. MARTIN e G. VOSS, 1975. Ths substituted Ureas. In: Herbicides - Chemistry, degradation and mode of action. KEARNEY P.C. e D.D. KAUFMAN. 2a. ED. New York, Marcel Dekker Inc. p. 209 - 291.

GORROD, J.W., D.J. TEMPLE e A.H. BECKETT, 1970. The formation of $\mathrm{N}$ - hydroxymethilcarbazole as a metabolite of $\mathrm{N}$ - methylcarbazole. Biochem. J. 117 (2) , 40 p.

GUIMARĀES, G.L., 1977. Aspectos diferenciais na fotossíntese de plantas $\mathrm{C}_{3}$ e $\mathrm{C}_{4}$. Seminário apresentado na Disciplina Metabolismo Intermediário de Plantas. Escola Superior de Agricultura "Luiz de Queiroz". Piracicaba - Mimeogra fado. $20 \mathrm{p}$.

GUTIERREZ, L.E., 1970. Atividade de enzimas relacionadas com a assimilação do nitrogênio afetada pela deficiência de 
potássio e maturidade em feijoeiro ( Phaseolus vulgaris. L.). Tese de Doutoramento apresentada ao Instituto de Química, Universidade de São Paulo. 108 p.

HAUN, J.R. e J.H. PETERSON, 1954. Translocation of 3- ( p chlorophenyl ) - 1,1 - dimethylurea in plants. Weeds,3: 177 - 187 .

HERBICIDE HANDBOOK:, 1979. Weed Science Society American. Fourth Edition. p 430-433

HILL, G.D. e J.W. MCGAHEN, 1955. Proc. South. Weed Control. Conf.. 8: 284 .

JARDIM et alii, 1965. Contribuição ao estudo da composição química de plantas forrageiras de pastagens do Brasil Central. In: Anais do IX Congresso Internacional de Pas tagens - S.P. Brasil - v-1 - p. 696 - 704 .

JOHNSON, R.N., T.L. BALWANII, L.L. JONSON, K.E. MCCLUE e B.A. DEHORITY, 1966. Corn plant maturity II. Effect on in vitro celulose digestibility and soluble carbohydrates content. J. Animal Sci. 25: 617-623

KEANEY, P.C. e W.K. KENNEDY, 1962. Relationship between losses of fermentable sugars and changes of organic acids in silage. Agronomy J. 54: $114-155$.

KLINE, R.M., J. W. KNOX e W. J. BEGUE, 1975. The effect of EL - 103 on soil microorganisms. Lilly Research Labora tories. Indianapolis, Indiana, U.S.A.. Mimeografado $32 \mathrm{p}$. 
KLINGMAN, G.C. e F.M. ASHTON, 1975. Weed Science: Principlès and practices. U.S.A. John Wiley and Sons, Inc. 431 p.

LAETSCH, W.M., 1974. The C4 Syndrome: A Structural analysis Ann. Rev. Plant Physiol., 25: 27-52.

LEMOS, P.N. e M. CORSI, 1981. O Colonião, Panicum maximum, Jacq. Apostila mimeografada. Departamento de Zootec nia. Escola Superior de Agricultura " Luiz de Queiroz". Piracicaba. 243p.

LILLY, RESEARCH LABORATORIES, 1977. Estudos de degradação com Tebutiuron. Indianapolis, Indiana, U.S.A. Mimeografado $16 \mathrm{p}$.

LUDLOW, M.M. e G.L. WILSON, 1972. Photosynthesis of tropical pasture plants. IV Basis and consequence of differen ces between grasses and legumes. Aust. J. Biol. Sci,25, 1133 - 45 .

LUDLOW, M.M. e T.T. NG, 1976. Effect of water deficit on car bon dioxide exchange and leaf elongation rate of Panicum maximum var. trichoglume. Aust. J. Plant Physiol.,3: $401-13$.

MAGNUSSEN, J.D. e D.P. RAINEY, 1977. Metabolism of Tebuthiuron in range grasses. Abstr. Pap. Amer. Chem. Soc. 173 d: PEST. 43 .

MCCOSTER, T.M. A J.K. TEITZEL, 1975. A review of Guinea grass ( Panicum maximum) for the wet tropics of Austrália. In: Tropical Grasslands - queensland, Austrália. 9 (3):177 190. 
MC MAHON, R.E. e H.R. SULLIVAN, 1965. The metabolism of the herbicide diphenamid in rats. Biochem. Pharmac.14 1085.

MITIDIERI, J., 1977. Taxonomia de p̈lantas forrageiras. I Gramíneas. Apostila mimeografada. . Centro Acadêmico "Luiz de Queiroz" . "Luiz de Queiroz". Piracicaba, S.P. 116-122.

MORTON, D.M. E D.G. HOF FMAN, 1976. Metabolism of a new herbicide Tebuthiuron 1 - (5 - (1,1 dimethyl - 1,3,4thiadiazol - 2 - yl) - 1,3 dimethylurea) in mouse, rat, rabbit, dog, duck and fish. J. Toxicol. Environ. Health, 1 : $757-768$.

MURRAY, D.S., W.L. RIECK e J.Q. LIND, 1969. Microbial degradation of five substituted urea herbicides. Weed Science $17: 52$.

OTERO, J.R., 1961. Informaçōes sobre algumas plantas forrageiras. Série Didática no 11; Serviço de .'Infộrmação Agrícola. Rio de Janeiro.

PEDREIRA, J.V.S., 1972. Crescimento estacional dos capins colonião (Panicum maximum) Jacq, gordura (Melinis minu tiflora Pal de Beauv.), Jaraguá (Hyparrhenia rufa (Ness) Stapf) e pangola de Taiwan A - 24 (Digitaria pentzii. stent). Tese de Doutoramento. Escola Superior de Agricultura "Luiz de Queiroz". Piracicaba, S.P.

PETERSON, R.A., 1970. Efeito do corte ou pastoreio sobre as plantas In: Fundamentos de manejo de pastagens; Instituto de zootecnia. Secretaria da Agricultura. são Paulo, S.P. - 246 p. 
PETERSON, R.A., 1970. Energia radiante. In: Fundamentos de. manejo de pastagens: Instituto de zootecnia. Secreta ria da Agricultura. São Paulo, S.P. 246 p.

PIMENTEL, GOMES, F., 1970. Curso de Estatística Experimental. $48 \mathrm{Ed}$. Escola Superior de Agricultura "Luiz de Queiroz" Piracicaba. S.P.

PUPO, N.I. H., 1980. Manual de Pastagens e Forrageiras. Ins tituto Campineiro de Ensino Agrícola. 28 Ed. 343 p.

RAINEY, D.P., J.D. MAGNUSSEN e R.J. HERBEG, 1976. Determination and characterization of radioactive residues in milk from a cow givem ${ }^{14} \mathrm{C}$ Tebuthiuron. Lilly Research Laboratories. Indianapolis, Indiana, U.S.A.. Mimeografado $21 \mathrm{p}$.

ROUQUETTE, F.M., 1978. Effect of Tebuthiuron on nutritive va lue of weeping lovegrass (Eragrostic curvula). Texas Agricultural Experiment Station. Texas, U.S.A. Apre sentação feita no Graslan Symposium.

RYLE, G.J.A. e J.D. HESKETH, 1969. Carbon dioxide uptake in nitrogen deficient plants. Crop. Sci. 9: 451

SERRĀO, E.A.S. e I.C. FALESI, 1977. Os trópicos ünidos. In: Anais do 49 Simpósio sobre manejo da pastagem. Fundação Cargill. Escola Superior de Agricultura " Luiz de Quei roz ". Piracicaba, S.P.. 177-247.

SHROYER, J.P., J.F. STRITZKE E L.I. CROY, 1977. Effects of Tebuthiuron and 2,4,5 - T ou carbohydrate levels in win ged elm and blackjack oak. Proc. South. Weed Sci. Soc. 30: 355 . 
SOSEBEE, R.E., 1979. Influence of Tebuthiuron on forage quality of selected grasses. Preliminary evaluations. Proc. South. Weed Sci Soc., 32: 334 - 346 .

STEIÎTERT, W.G. e J.F. STRITZKE, 1977. Uptake and phytotoxicity of Tebuthiuron. Weed Sci, 25: $390-395$.

TIBAU, A.O., 1978. Gramíneas. In: Pecuāria Intensiva. Livraria Nobel S/A. 4a. Ed. - São Paulo, S.P., 38-44.

TODD, G.C., W.R. GIPSON e C.C. KEHR, 1974. Oral toxicity of Tebuthiuron 1 - (5-tert-butyl-1,3,4-thiadiazol-2-yl) 1,3 - dimethylurea) in experimental animals. Food Cosmet. Toxicol. , 12 (4) : $461-470$.

TWEEDY, B.G., C. Loe PPKI e J. A. ROSS, 1970. Metabolism of 3-(p-Bromophenyl)-l-methoxi-l-methylurea (Metabromuron) by selected soil microorganisms. J. Agric. Food Chem. 18: 851 .

WALSCH, G.E. e T.E. GROW, 1971. Depression of carbohydrate in marine algae by urea herbicides. Weed Sci, 19, : 568 570 .

WEINBERGER, M., 1972. M. Sc. Thesis. Pennsylvania State University, University, Park, March.

WESSELS, J.S.C. e R. VAN DER VEEN, 1956. The action of some derivatives of phenylurethan and of 3 - phenły - 1,1 dimethylurea on the Hill reaction. Biochem et Biophys. Acta, $19: 548-549$.

WILSON, J.R., 1975. Influence of temperature and nitrogen on growth, photosynthesis and accumulation of non-structural carbohydrate in a tropical grass, Panicum maximum var. trichoglume.Neth. J. Agric. Sci. 23 : 48-61. 


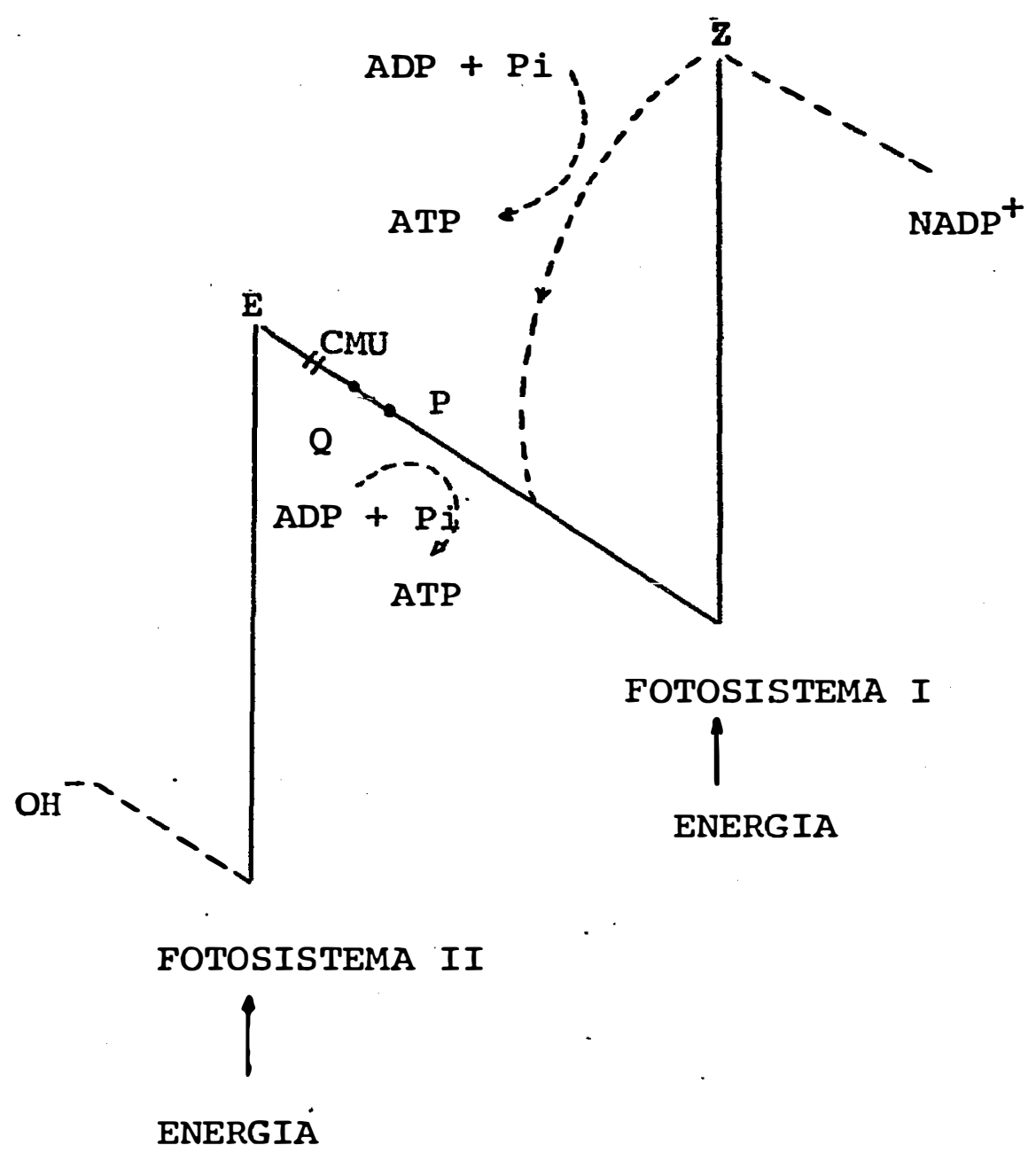

Esquema para o transporte do eletron fotossintético mostrando o sítio de ação do inibidor CMU. E, P, e $Q$ são carregadores de eletrons hipotéticos e z é o aceptor primário de eletrons do fotosistema I 


\section{APÊNDICE B}

TABELA DE DADOS SOBRE TEMPERATURA E PRECIPITAÇÃO

\begin{tabular}{lccccc}
\hline & $\begin{array}{c}\text { T. MAX } \\
\left({ }^{\circ} \mathrm{C}\right)\end{array}$ & DIA & $\begin{array}{c}\text { T. MIN } \\
\left({ }^{\circ} \mathrm{C}\right)\end{array}$ & DIA & $\begin{array}{c}\text { PRECIPITAÇÃO } \\
(\mathrm{mm})\end{array}$ \\
\hline FEVEREIRO & 37 & $\begin{array}{l}7,8 \\
\mathrm{e} 10\end{array}$ & 17 & 15 & 131,7 \\
\hline MARÇO & 37 & 9 & 15 & 25,27 & 102,3 \\
\hline ABRIL & 33 & 2,3 & 11 & 7 e & 28 \\
\hline MAIO & 30 & 19 & 8 & $24 \mathrm{e}$ & 142,8 \\
\hline JUNHO & 28 & 13 & 252,1 & - \\
\hline
\end{tabular}

